УДК 547.458

\title{
ПОЛИСАХАРИДЫ. СОВРЕМЕННОЕ СОСТОЯНИЕ ИЗУЧЕННОСТИ: ЭКСПЕРИМЕНТАЛЬНО-НАУКОМЕТРИЧЕСКОЕ ИССЛЕДОВАНИЕ
}

\author{
() Д.Н. Оленников", Н.И. Кащенко \\ Институт общей и экспериментальной биологии СО РАН, ул. Сахьяновой, 6 , \\ Улан-Удэ, 670047 (Россия), e-mail: oldaniil@rambler.ru
}

В обзоре представлены результаты наукометрического изучения сведений научной литературы о состоянии изученности одной из распространенных групп природных полимеров - полисахаридов. Для выполнения исследования были использованы ресурсы научной базы данных Scopus. Проведено обобщение информации о полисахаридных компонентах растительных видов, разрешенных к применению в медицинской практике в России (112 видов), а также представлены сведения о распределении полисахаридных классов по морфологическим группам растений. Экспериментальная часть работы включала определение содержания и групповой принадлежности водорастворимых полисахаридов 84 официнальных растительных видов, для 56 из которых подобное исследование было осуществлено впервые.

Ключевые слова: полисахариды, наукометрический анализ, ключевое слово, циитирование, официнальные растительные виды, морфологические группы.

Биополимеры как обязательный компонент любой живой клетки привлекают внимание исследователей разных отраслей науки. К биополимерам относятся различные классы соединений, в т.ч. белковой (белки), углеводной (полисахариды), фенольной (меланины, таннины, гуминовые и фульвокислоты) и смешанной природы (липополисахариды, гликопротеиды и др.). Учитывая тот факт, что к настоящему времени в экспериментальной науке накоплен колоссальный объем научной информации, касающейся различных сфер знаний о биополимерах, нами проведено наукометрическое исследование имеющихся сведений. Для проведения данного исследования нами были использованы ресурсы научной базы данных Scopus как наиболее полного источника научной информации, с привлечением такого критерия, как «ключевое слово» в разделах названия статей, резюме, списке авторов, тип публикации и др. ${ }^{* *}$

Наукометрические показатели степени изученности класса полисахаридов. Количество научной информации, относящейся к разным классам биополимеров, неодинаково. Так, принимая во внимание количество материала, относящегося к исследованию 6 наиболее изучаемых классов полимеров, можно заметить, что около $97 \%$ (около 3,7 млн ссылок) статей посвящено изучению белков и около $3 \%$ - полисахаридов; число ссылок по фенольным полимерам не превышает 0,5\% (рис. 1).

Согласно сведениям БД Scopus общий объем научных работ, классифицируемых по ключевому сло-

Оленников Даниил Николаевич - старший научный сотрудник лаборатории медико-биологических исследований, доктор фармацевтических наук, e-mail: oldaniil@ rambler.ru

Кащенко Нина Игоревна - аспирант лаборатории медико-биологических исследований ву «полисахарид», за 1900-2011 гг. составляет около 100 тыс. Распределение количества ссылок по годам свидетельствует о различной степени интереса к данному классу природных соединений в течение XXXXI вв. (рис. 2).

\footnotetext{
${ }_{* *}^{*}$ Автор, с которым следует вести переписку.

** Следует указать, что при проведении подобных исследований заранее предполагается существование некоторого вероятностного характера полученных данных вследствие несовершенности поисковых результатов по критерию ключевого слова. Согласно последним исследованиям относительная ошибка определения числовых показателей наукометрических исследований составляет $\pm 10-15 \%$ от полученной величины.
} 

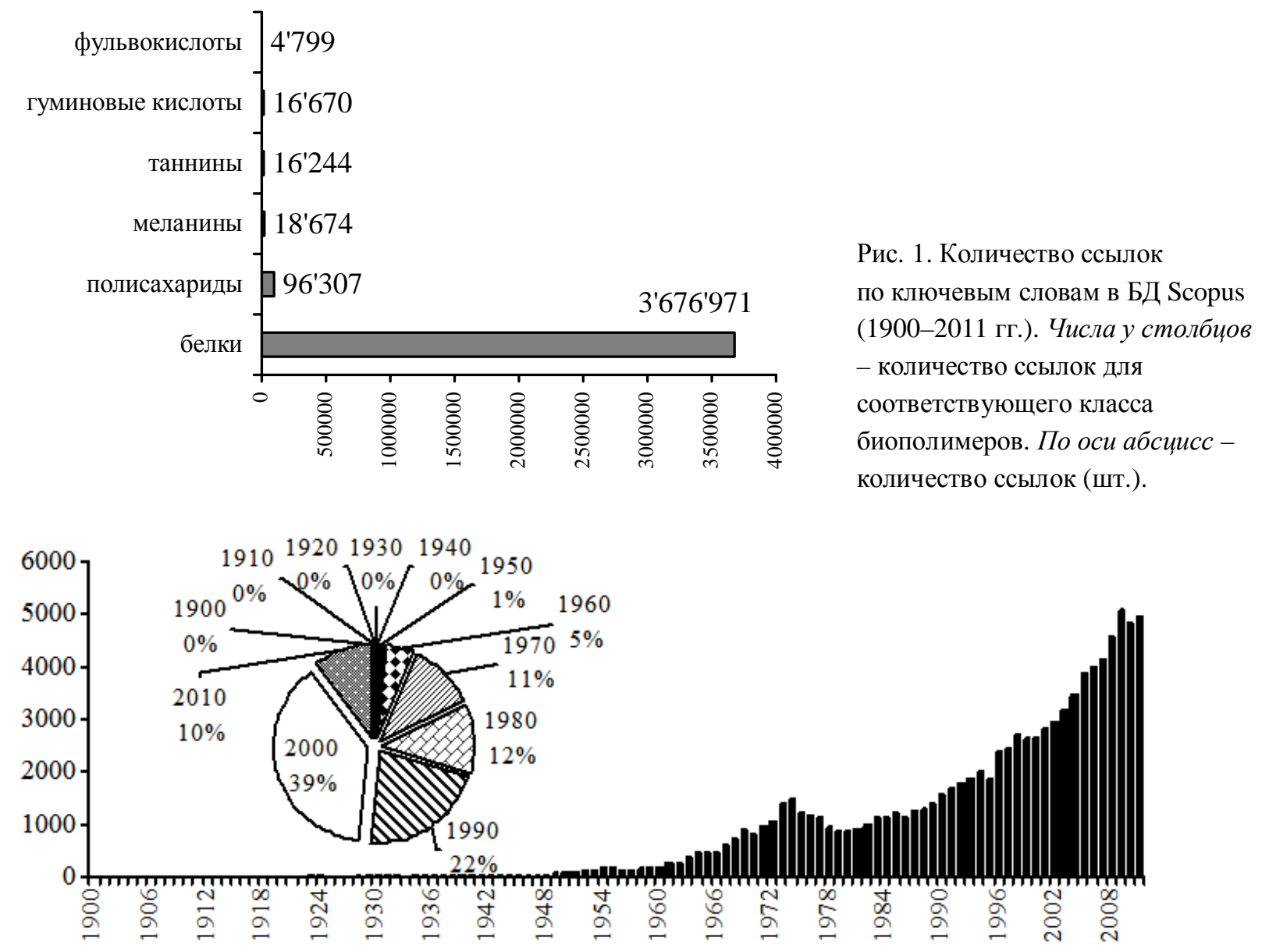

Рис. 2. Распределение количества статей с ключевым словом «polysaccharide» по годам (1900-2011). На круговой диаграмме - распределение количества статей по десятилетиям (в процентах указан вклад каждого десятилетия в общее количество статей)

Так, первое упоминание в научных журналах XX в., касающееся исследования полисахаридов, относится к 1900 г. - статья J.L. Bakker и T.H. Роре о галактане Strychnos popatorum и маннане Phytelephas macrocarpa [1]. Дальнейший интерес к полисахаридным компонентам, вплоть до 1960 г., был недостаточным: исследовательский вклад этого временного периода в общее число публикаций составляет около $1 \%$.

Развитие научной мысли в области биохимии, физиологии, медицины и техники, экспериментальные данные о важной роли углеводных биополимеров в регуляции биологических процессов, а также сведения об их прикладном значении в различных отраслях человеческой деятельности побудили научную общественность к проведению развернутых и крупномасштабных исследований этих соединений. Данные обстоятельства убедительно отразились на объеме научных статей, количество которых с каждым десятилетием увеличивалось. Так, если в 60-х гг. было опубликовано около 4,5 тыс статей, то в 2000-х гг. эта цифра составила более 37 тыс.

Рассмотрение исследовательских направлений химии полисахаридов свидетельствует о том, что наибольшее число работ относится к области биохимии, генетики и молекулярной биологии (38\% от общего числа работ $\left.{ }^{1}\right)$, медицине $(27 \%)$, иммунобиологии и микробиологии (22\%), структурной химии (17\%), сельскохозяйственным наукам (15\%) и материаловедению (7\%).

Характер распределения статей по ключевым словам помогает установить наиболее популярные экспериментальные задачи (табл. 1). Взяв в рассмотрение 30 часто используемых ключевых слов, можно предположить, что наибольший интерес вызывают работы, связанные с бактериальными и грибными объектами, методами исследования (ЯМР, МС, ВЭЖХ, ГПХ), классами полисахаридов (липополисахариды, целлюлоза, крахмал, пектин), их свойствами (растворимость, вязкость), функциями (метаболизм, биосинтез) и областями применения (генетика, иммунология).

\footnotetext{
${ }^{1}$ Следует отметить, что исследования зачастую носят смежный с другими направлениями характер.
} 
Таблица 1. Распределение статей по ключевым словам

\begin{tabular}{l|c|l}
\hline \multicolumn{1}{c|}{ Ключевое слово } & $\%^{*}$ & \multicolumn{1}{c}{ Ключевое слово } \\
\hline Бактериальные полисахариды & 14,6 & Масс-спектрометрия \\
Метаболизм & 9,7 & Генетика \\
ЯМР & 6,8 & Гликопротеины \\
Иммунология & 5,3 & Клеточная культура \\
Липополисахариды & 5,0 & Растворимость \\
Анализ углеводов & 4,7 & Вязкость \\
Молекулярная масса & 4,5 & Гель-хроматография \\
Биосинтез & 4,3 & Вэжх \\
Гидролиз & 3,9 & Иммуносорбенты \\
Выделение и очистка & 3,7 & Ферментация \\
Антитела & 3,7 & Грибы \\
Клеточная стенка & 3,6 & Электронная микроскопия \\
Целлюлоза & 3,2 & Крахмал \\
Бактериальные антигены & 3,2 & Метилирование \\
Энзимология & 2,1 \\
\hline
\end{tabular}

* От общего числа статей.

К числу наиболее цитируемых статей относятся, как правило, работы методического плана (фенолсерный метод Дюбуа, метод определения клетчатки, метод метилирования по Хакомори) и обзоры по различным типам полисахаридов и их применению (пептидогликаны, гиалуронан, липополисахариды, хитин и др.) (табл. 2).

Принимая во внимание разнообразие структурных типов полисахаридов, мы рассмотрели степень научного интереса к различным классам соединений. Установлено, что около 70\% научных работ посвящено исследованию целлюлозы (45\%) и крахмала (23\%) как наиболее важных технических объектов (рис. $3 a$ ). Обнаруженные уникальные свойства глюкозаминанов - хитина и хитозана, инициировали возрастающий научный интерес к ним (около 14\% публикаций); существенное количество работ проводится по изучению инулина, каррагенанов, пектинов и альгиновых кислот (около 5\% для каждого класса). Рассмотрение изученности химических типов полисахаридов (классификация по доминирующему моносахариду) указывает на повышенный интерес к запасным компонентам - глюканы (амилоиды и близкие к ним полимеры) и маннаны, и составляющим клеточной стенки - целлюлоза и ксиланы (рис. 3б).

О наличии неубывающего интереса к указанным углеводным полимерам свидетельствуют высокие показатели цитирования (более 200 цит.) отдельных статей, касающихся обобщения научного материала или предметного исследования свойств, строения или функций этих полисахаридов (табл. 3 ).

Анализ исследовательских предпочтений в сфере химии полисахаридов при выборе объекта исследования показывает, что наиболее часто изучаемыми являются микроорганизмы (до 58\% случаев); до $32 \%$ приходится на объекты растительного происхождения и только около $10 \%$ - на грибы. Для растений самой исследуемой морфологической группой является надземная часть (листья, цветки, стебли) - до 52\% случаев; исследования полисахаридов корней и семян составляют 20 и $28 \%$ соответственно. Большего интереса среди грибов удостаиваются микромицеты (79\%); доля химической информации о полисахаридах макромицетов не превышает $21 \%$.

Таблица 2. Наиболее цитируемые статьи, посвященные полисахаридам, за 1900-2011 гг.

\begin{tabular}{l|c}
\hline \multicolumn{1}{c}{ Статья } & Цит. \\
\hline Dubois M., et al. Colorimetric method for determination of sugars and related substances [2] & 12388 \\
Van Soest P.J., et al. Methods for dietary fiber, neutral detergent fiber, and nonstarch polysaccharides in relation & 6508 \\
to animal nutrition [3] & 1550 \\
Carpita N.C., Gibeaut D.M. Structural models of primary cell walls in flowering plants: Consistency of molecu- & \\
lar structure with the physical properties of the walls during growth [4] & 1320 \\
Schleifer K.H., Kandler O. Peptidoglycan types of bacterial cell walls and their taxonomic implications [5] & 1198 \\
Raetz C.R.H., Whitfield C. Lipopolysaccharide endotoxins [6] & 1182 \\
Laurent T.C., Fraser J.R.E. Hyaluronan [7] & 1082 \\
Ravi Kumar M.N.V. A review of chitin and chitosan applications [10] & 1059 \\
Helenius A., Aebi M. Intracellular functions of N-linked glycans [8] & 993 \\
Hakomori S.-I. A rapid permethylation of glycolipid, and polysaccharide catalyzed by methylsulfinyl carbanion \\
in dimethyl sulfoxide [9]
\end{tabular}



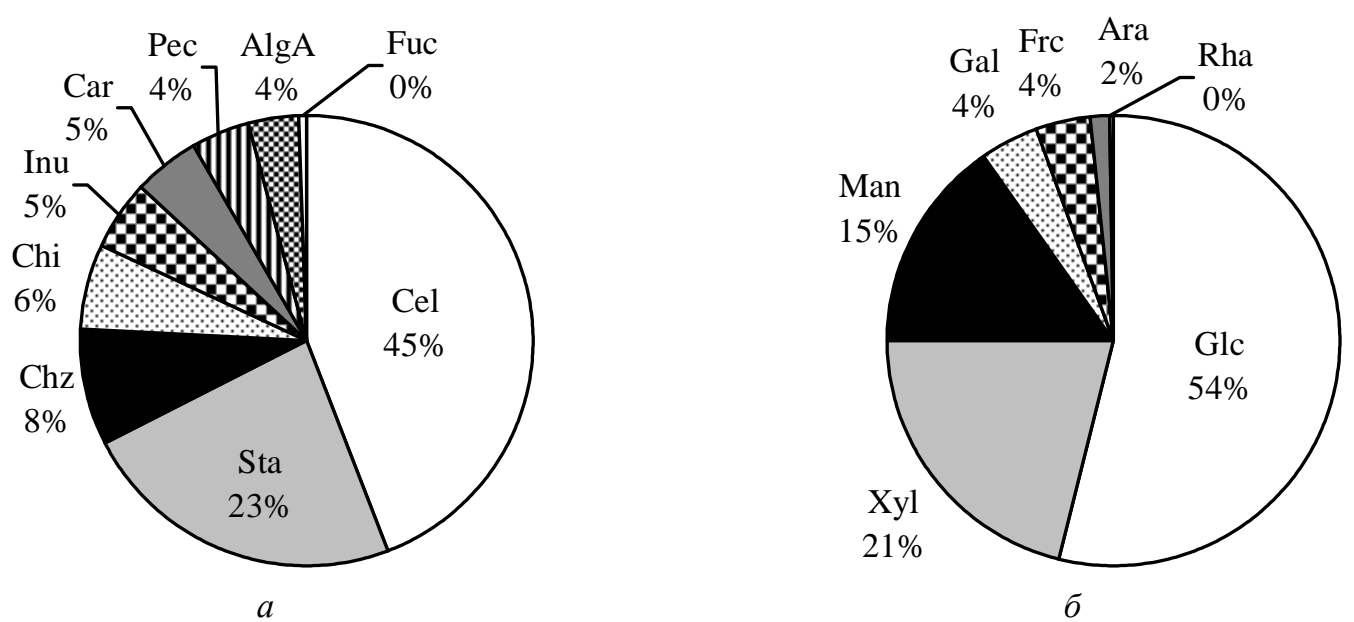

Рис. 3. Распределение научных статей по изучению различных типов полисахаридов: $a$ - отдельные представители полисахаридов (AlgA - альгиновые кислоты, Car - каррагенаны, Cel - целлюлоза, Сhi хитин, Chz - хитозан, Fuc - фукоиданы, Inu - инулин, Pec - пектин, Sta - крахмал); б - химические типы полисахаридов (Ara - арабинаны, Frc - фруктаны, Gal - галактаны, Glc - глюканы, Man маннаны, Rha - рамнаны, Xyl - ксиланы)

Таблица 3. Наиболее цитируемые статьи за 1900-2011 гг. по отдельным классам полисахаридов

\begin{tabular}{lc}
\hline \multicolumn{1}{c}{ Статья } & Цит. \\
\hline Крахмал: Englyst H.N., et al. Classification and measurement of nutritionally important starch fractions [11] & 823 \\
Хитин, хитозан: Ravi Kumar M.N.V. A review of chitin and chitosan [10] & 1082 \\
Инулин: Gibson G.R., et al. Selective stimulation of bifidobacteria in the human colon by oligofructose & 724 \\
and inulin [12] & 254 \\
Каррагенан: Stevenson T.T., Furneaux R.H. Chemical methods for the analysis of sulphated galactans & \\
from red algae [13] & 565 \\
Пектин: Ridley B.L., et al. Pectins: Structure, biosynthesis, and oligogalacturonide-related signaling [14] \\
Альгиновая кислота: Rowley J.A., et al. Alginate hydrogels as synthetic extracellular matrix materials [15] \\
Фукоидан: Patankar M.S., et al. A revised structure for fucoidan may explain some of its biological activi- \\
ties [16]
\end{tabular}

Наравне с полимерными компонентами растительных и грибных объектов проводятся исследования низкомолекулярных соединений, интерес к которым в ряде случаев значительнее такового к полисахаридам. Проведя сравнительный анализ информации о метаболитах трех самых крупных растительных семейств, было выявлено, что количество статей, посвященных изучению полисахаридов сем. Fabaceae не превышает $28 \%$, для сем. Asteraceae этот показатель составляет 15\%, а для сем. Lamiaceae - не превышает $1 \%$, что указывает на крайне низкую степень изученности биополимеров этих семейств (рис. 4).

Данный показатель для рода Larix равен около 69\%, что обусловлено, в первую очередь, широкомасштабными исследованиями целлюлозных компонентов и арабиногалактанов. Условным лидером по степени изученности углеводов является род Laminaria, статьи по изучению полисахаридов которого составляют около $90 \%$ от общего объема печатного материала. Для базидиомицетов количество научных статей, посвященных изучению полисахаридов, составляет $42 \%$.

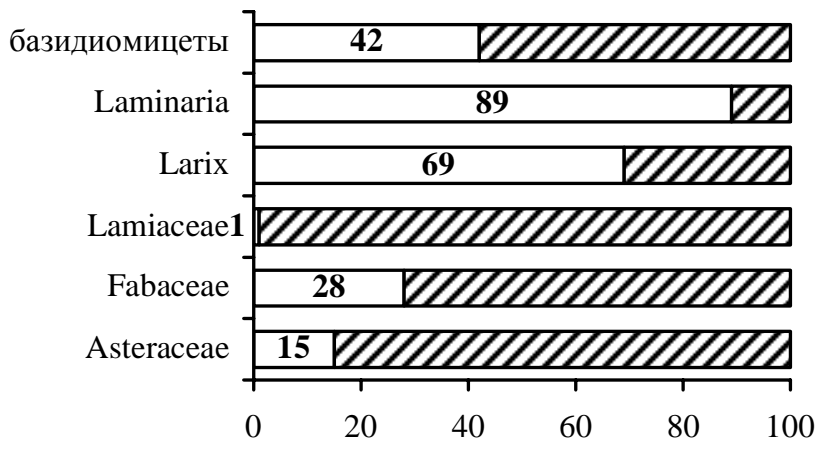

Рис. 4. Соотношение количества научных статей, посвященным изучению полисахаридов (белый) и низкомолекулярных метаболитов (штриховка), \% 
Для отдельных объектов исследования отмечается особый повышенный интерес, что связано с наличием у полимеров уникальных химических и функциональных свойств, или биологической активности. Так, к наиболее часто исследуемым объектам растительного происхождения относятся виды Arabidopsis (модельный объект для многих исследовательских задач), Zea mays, Solanum tuberosum (крахмалы), Panax ginseng (уникальные типы галактуронанов), Astragalus sp. (биологически активные глюканы). Среди грибных объектов наиболее «популярными» являются представители дрожжей и микромицетов (Aspergillus, Candida, Cryptococcus, Saccharomyces). Исследованию базидиальных видов уделяется значительно меньшее внимание, но несмотря на это особенно следует выделить рода Agaricus, Coriolus, Flammulina, Ganoderma, Grifola, Lentinus, являющихся перспективными источниками соединений, обладающих противоопухолевой активностью.

О высокой степени изученности ряда направлений в химии полисахаридов свидетельствует наличие обзорных работ, посвященных обобщению фактического материала, касающегося ${ }^{2}$ :

- полисахаридов растительных видов (Angelica sinensis [17], Ginkgo biloba [18], Panax ginseng [19], Tamarindus indica [20], Trigonella foenum-grecum [21]);

- полисахаридов грибных видов (Cordyceps [22]);

- химических полисахаридных групп (арабиногалактаны [23], галактоманнаны [24-26], глюканы [27], пектины [28, 29], сульфатированные фуканы [30]);

- полисахаридных групп по происхождению (грибы [31], древесные виды [32], лишайники [33], морские организмы [34]);

- индивидуальных полисахаридов (арабиногалактан лиственницы [35], инулин [36], курдлан [37], курестин [38], рамногалактуронан типа II [39, 40], склероглюкан [41]);

- фармакологической активности полисахаридов (иммуномодулирующая [42-45], противоопухолевая [46], противовирусная [47]).

Совершенствование методологии анализа структуры полисахаридов, улучшение существующих и создание новых методов исследования отражается на качестве экспериментального материала, представленного в статьях. Принимая во внимание особенности представления данных при описании структуры полисахаридов, мы выделели пять основных (наиболее часто используемых) характеристик: моносахаридный состав, молекулярная масса, тип и состав связей между моносахаридами, конфигурация аномерных центров и физические свойства (вязкость, рН растворов, оптическое вращение и др.) (табл. 4). Установлено, что за период с 1930 по 2011 г. наблюдается отчетливая тенденция к уменьшению количества этапов при установлении строения полисахаридных макромолекул. В частности, частота встречаемости данных о моносахаридном составе и молекулярной массе полимеров возросла с 19 до 99\% и с 2 до $98 \%$ соответственно. Причиной данного факта является повышение доступности высокоэффективных методов анализа (гель-проникающая хроматография, масс-спектрометрия) для исследователей, а также широкое использование недеструктивных методов установления структуры, таких как, например, метод ЯМР.

Анализ имеющейся информации показывает, что в настоящее время наиболее часто используется метод газо-жидкостной хроматографии, применимость которого составляет до $91 \%$ экспериментальных работ (рис. 5). Высокими показателями значимости обладают спектральные (ЯМР, ИК, УФ-Вид) и другие хроматографические методы (ГПХ, ВЭЖХ) - 70-82\%. Особое внимание уделяется новым хайфенированным (комбинированным) методам, позволяющим расширять диапазон получаемой экспериментальной информации, таким как газовая хроматография-масс-спектрометрия (ГХ/MC), высокоэффективная хроматография-масс-спектрометрия (ВЭЖХ/МС) и др.

Таблица 4. Частота определения индивидуальных характеристик при определении структуры полисахаридов, \% от общего числа работ за данный временной интервал*

\begin{tabular}{l|c|c|c|c|c}
\hline \multicolumn{1}{c}{ Характеристика } & \multicolumn{5}{c}{ Годы } \\
\cline { 2 - 6 } & $1930-1950$ & $1950-1970$ & $1970-1990$ & $1990-2000$ & $2000-2011$ \\
\hline Моносахаридный состав & 19 & 57 & 82 & 98 & 99 \\
Молекулярная масса & $<2$ & 47 & 53 & 87 & 98 \\
Тип и состав связей между моносахаридами & $<1$ & 15 & 43 & 51 & 76 \\
Конфигурация аномерных центров & 5 & 23 & 62 & 80 & 92 \\
Физические свойства & 83 & 87 & 82 & 79 & 61 \\
\hline
\end{tabular}

* Выборка была построена из 20\% наиболее репрезентативных и наиболее цитируемых статей (полных исследовательских публикаций).

\footnotetext{
${ }^{2}$ Приведены ссылки на работы не позднее 2000 г.
} 
Учитывая возрастающий интерес к исследованию полисахаридов, издательские компании увеличивают количество специализированных журналов, посвященных экспериментальным работам в данном направлении. К наиболее известным относятся журналы Carbohydrate Research, Carbohydrate Polymers, Food Hydrocolloids, Biomacromolecules, Macromolecules, International Journal of Macromolecules и др. Согласно статистическим данным к числу пяти часто используемых для публикации журналов относятся Carbohydrate Research, Journal of Biological Chemistry, Carbohydrate Polymers, Infections and Immunity и Journal of Bacteriology, общий объем публикаций в которых составляет более $15 \%$ от таковых по данной теме (рис. 6).

Доля журнальных статей в общем объеме публикаций составляет 96,3\%, книжных серий - 1,1\% и книг - менее $0,1 \%$. Более $80 \%$ статей представляют собой полные исследовательские публикации, 6,4\% - обзоры, $4,1 \%$ - материалы конференций и около $1 \%$ - краткие сообщения и записки. Англоязычные издания занимают лидирующее место по публикациям, посвященным полисахаридам - 88,5\%, для русскоязычных изданий эта величина составляет 2,6\%; на остальные языки приходится менее $10 \%$, в том числе китайский - 2,3\%, немецкий $-1,6 \%$, японский - $1,3 \%$, французский - $1,2 \%$ и итальянский $-0,4 \%$.
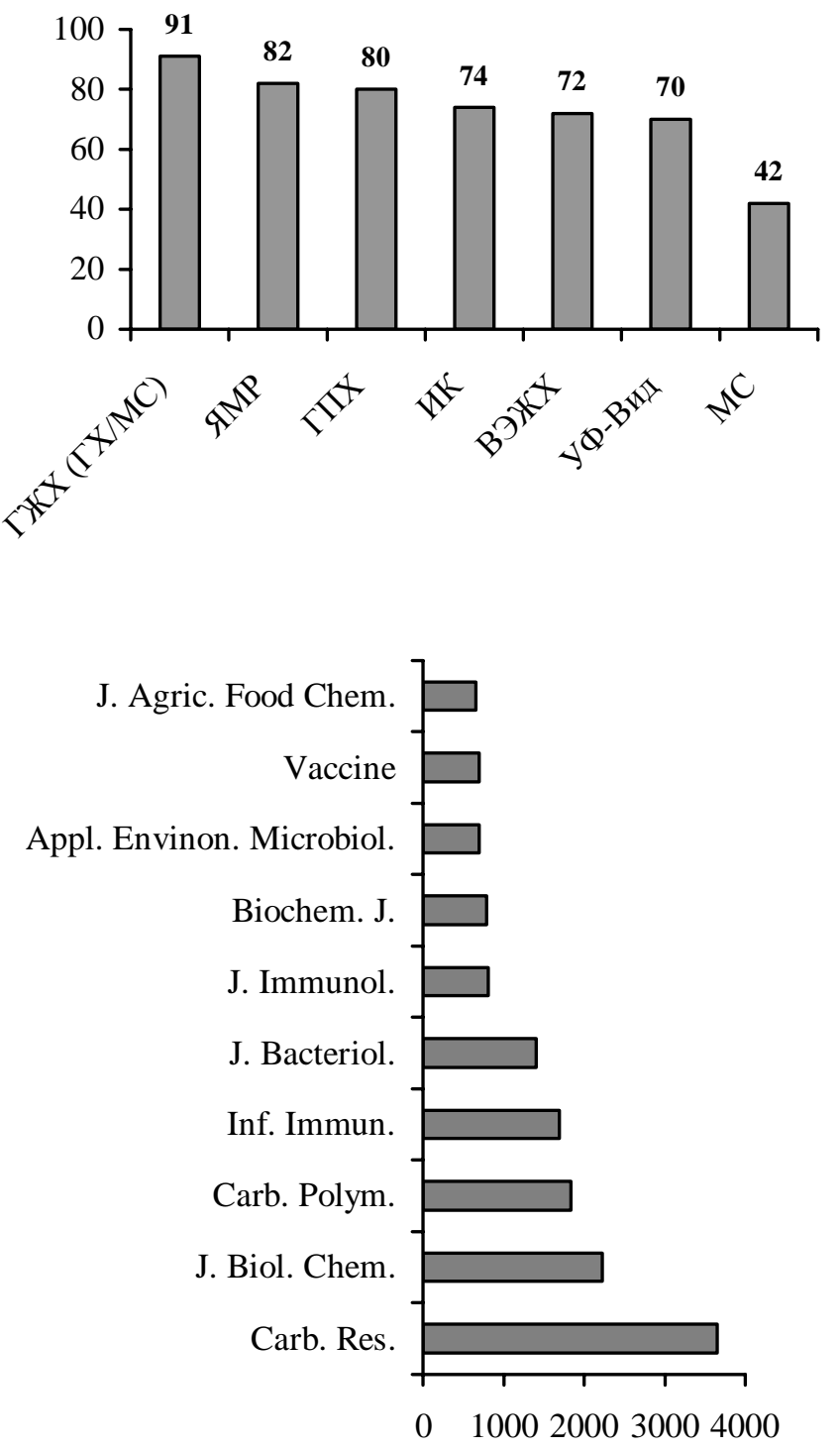

Рис. 5. Частота использования различных физико-химических методов при определении структуры полисахаридов (по данным за 2000-2011 гг.). По оси абсичисс - метод, по оси ординат процент от общего числа работ за данный временной интервал ${ }^{3}$
Рис. 6. Количество статей с ключевым словом «полисахарид» в 10 наиболее часто используемых для публикации журналах

\footnotetext{
${ }^{3}$ Выборка была построена из наиболее репрезентативных и цитируемых статей (полных исследовательских публикаций), составляющих около $25 \%$ от общего числа статей.
} 
Полисахариды официнальных растительных видов России. В настоящее время в России к числу официнальных относятся 296 растительных видов. Установлено, что информация о характеристике или структуре полисахаридов имеется для 112 видов (около 38\% от общего числа) (табл. 5). Данные литературы о наличии, количественном содержании или природе полисахаридов отсутствуют для $62 \%$ видов представителей 52 семейств.

Учитывая сведения о полисахаридах с установленной структурой, можно заметить, что галактуронаны являются наиболее часто изучаемой группой полимеров (около 36\%), причем рамногалактуронаны (80\% от общего числа галактуронанов) встречаются гораздо чаще, чем гомогалактуронаны (рис. 7). На долю биогенетически родственных галактанов приходится 27\% выделенных полисахаридов, более $80 \%$ из них составляют арабиногалактаны. Меньше встречаются глюканы (14\%), маннаны (8\%) и другие классы полимеров. Наибольший научный интерес вызывают полимеры семейства Asteraceae (13 видов из 23), Fabaceae (9 видов из 18), Rosaceae (7 видов из 13) и Lamiacae (5 видов из 10).

Для некоторых растительных семейств информация о полисахаридах отсутствует, что делает их перспективными для дальнейшего изучения. К таковым можно отнести представителей Aristolochiaceae (Asarum eyropaeum), Ephedraceae (Ephedra equisetina), Fagaceae (Quercus petraea), Gentianaceae (Centaurium spp.), Magnoliaceae (Magnolia grandoflora), Melanthiaceae (Colchicum speciosum, Veratrum lobelianum), Oleaceae (Syringa vulgaris), Passifloraceae (Passiflora incarnata), Polemoniaceae (Polemonium caeruleum), Salicaceae (Populus nigra, Salix spp.), Scrophulariaceae (Digitalis grandiflora, Gratiola officinalis, Verbascum spр.) и др.

Рис. 7. Распределение структурных типов полисахаридов в официнарных растительных видах. Ar - арабинаны, $\mathrm{Fr}$ - фруктаны, $\mathrm{Fu}$ - фуканы, $\mathrm{Ga}$ - галактаны, Gl - глюканы, GalA - галактуронаны, GlcA - глюкуронаны, Mn - маннаны, Xl - ксиланы)

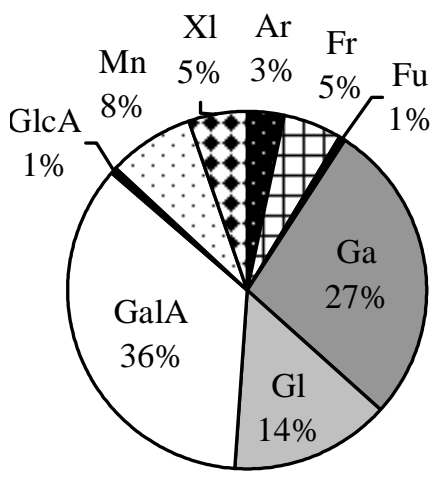

Таблица 5. Характеристика полисахаридов официнальных растительных видов России

\begin{tabular}{|c|c|c|}
\hline Вид & $\begin{array}{c}\text { Морфологическая } \\
\text { группа }\end{array}$ & Тип полисахарида(ов), доминирующий(ие) моносахарид(ы)* \\
\hline 1 & 2 & 3 \\
\hline \multicolumn{3}{|c|}{ Agavaceae } \\
\hline Yucca gloriosa & лист & ${ }^{\mathrm{CW}} \mathrm{Man} ;{ }^{\mathrm{HW}} \mathrm{Gal}, \mathrm{Ara} ;{ }^{\mathrm{PS}} \mathrm{Gal}, \mathrm{UA}$ [48] \\
\hline \multicolumn{3}{|c|}{ Alliaceae } \\
\hline Allium cepa & луковица & Gl-Fr (граминан), RG, RGII, Ar, AG, Xl-Gl [49-51] \\
\hline Allium sativum & луковица & 4,6-Ga, GU, Ar, Gl, Gl-Fr (граминан) [52-54] \\
\hline \multicolumn{3}{|r|}{ Amaranthaceae } \\
\hline Aerva lanata & трава & ${ }^{\text {WS }}$ Glc; ${ }^{\text {PS }}$ Gal, Glc; ${ }^{\text {HCA }}$ Glc; ${ }^{\mathrm{HCB}}$ Xyl, Glc [55] \\
\hline \multicolumn{3}{|r|}{ Amaryllidaceae } \\
\hline Ungernia sewerzowii, U. victoris & лист & ${ }^{\mathrm{WS}} \mathrm{Gal}, \mathrm{Frc} ;{ }^{\mathrm{PS}} \mathrm{Gal}$, GalA; ${ }^{\mathrm{HCA}} \mathrm{Gal}, \mathrm{Xyl} ;{ }^{\mathrm{HCB}} \mathrm{Glc}, \mathrm{Xyl}[56]$ \\
\hline \multicolumn{3}{|r|}{ Apocynaceae } \\
\hline Catharanthus roseus & лист & RG [57] \\
\hline Nerium oleander & лист & $\mathrm{RG}, \mathrm{AG}[58,59]$ \\
\hline Rauvolfia serpentina & корни & RG, GU, AG $[60,61]$ \\
\hline \multicolumn{3}{|c|}{ Araceae } \\
\hline Acorus calamus & корни & RG [62] \\
\hline \multicolumn{3}{|c|}{ Araliaceae } \\
\hline Aralia elata & корни & RG [63] \\
\hline Eleutherococcus senticosus & корни & Gl, Xl [64-66] \\
\hline & плоды & ${ }^{\mathrm{wS}} \mathrm{UA} 64 \%$, Gal [67] \\
\hline Panax ginseng & корни & $\alpha-4,6-G l$, GU, RG, RGI, RGII [19] \\
\hline
\end{tabular}


Продолжение таблищь 5

\begin{tabular}{|c|c|c|}
\hline 1 & 2 & 3 \\
\hline \multicolumn{3}{|c|}{ Aloaceae } \\
\hline Aloe arborescens & лист & GalA, Mn, RG [68-70] \\
\hline \multicolumn{3}{|c|}{ Apiaceae } \\
\hline Anethum graveolens & плоды & ${ }^{\text {ws }}$ Ara [71] \\
\hline Carum carvi & плоды & $\beta-1,4-\mathrm{Mn}[72]$ \\
\hline Coriandrum sativum & плоды & ${ }^{\text {ws }}$ Man, Xyl [71] \\
\hline Daucus carota & плоды & ${ }^{\text {ws }}$ Ara [71] \\
\hline Foeniculum vulgare & плоды & ${ }^{\text {ws }}$ Man [71] \\
\hline \multicolumn{3}{|c|}{ Asteraceae } \\
\hline Achillea millefolium & трава & Ara, Gal, GalA [73] \\
\hline Arctium lappa & корни & Gl-Fr (инулин), RG, AG, Xl-Gl [74, 75] \\
\hline Arctium tomentosum & корни & Gl-Fr (инулин, граминан) [76] \\
\hline Arnica montana & цветки & $\mathrm{RG}, \mathrm{GU}, \mathrm{AG}[77]$ \\
\hline Calendula officinalis & цветки & Rh-AG, AG [78] \\
\hline Centaurea cyanus & цветки & ${ }^{\mathrm{wS}}$ UA 79\%, Ara [79] \\
\hline Chamomilla recutita & цветки & RG, GlA-Xl, Gl-Fr, AG, AGP [80] \\
\hline Cichorium intybus & трава & Gl-Fr (инулин) [81] \\
\hline Echinacea purpurea & трава & Fu-Ga-Xl- $\beta-1,4-G 1$, AG, GlA-Ar-Xl [82-84] \\
\hline Inula helenium & корни & Gl-Fr (инулин) [85] \\
\hline Tanacetum vulgare & цветки & RGII $[86,87]$ \\
\hline Taraxacum officinale & корни & Frc, олиго-GFr, GFr $[88,89]$ \\
\hline Tussilago farfara & лист & AG, RGII [90] \\
\hline \multicolumn{3}{|c|}{ Berberidaceae } \\
\hline Berberis vulgaris & $\begin{array}{c}\text { лист } \\
\text { плоды }\end{array}$ & $\begin{array}{c}\alpha-1,4-\mathrm{Gl}(3,6), \beta-\mathrm{Xl}, \mathrm{Xl}-\mathrm{Gl}, \mathrm{AG} \text { [91] } \\
\text { ws Gal, Ara, GalA [92] }\end{array}$ \\
\hline \multicolumn{3}{|c|}{ Boraginaceae } \\
\hline Symphytum asperum & корни & Gl-Fr (граминан) [93] \\
\hline \multicolumn{3}{|c|}{ Brassicaceae } \\
\hline Brassica juncea & семя & $\operatorname{Ar}[94]$ \\
\hline \multicolumn{3}{|c|}{ Cannabiaceae } \\
\hline Humulus lupulus & сопл. & AGP, RG [95] \\
\hline \multicolumn{3}{|c|}{ Cladoniaceae } \\
\hline Cladonia alpestris & слоев. & $\alpha$-Gl (нигеран), Gl-Ga-Mn [33] \\
\hline \multicolumn{3}{|c|}{ Convallariaceae } \\
\hline Convallaria keiskei, C. majalis & трава & ${ }^{\mathrm{WS}}$ Glc, Ara; ${ }^{\mathrm{PS}}$ Gal, GalA [96] \\
\hline \multicolumn{3}{|c|}{ Elaeagnaceae } \\
\hline Hippophae rhamnoides & плоды & Gl-Mn-Ga [97] \\
\hline \multicolumn{3}{|c|}{ Ericaceae } \\
\hline Arctostaphylos uva-ursi & лист & $\alpha-4,6-G 1$, RG, Mn [98] \\
\hline Ledum palustre & побеги & RG [99] \\
\hline Oxycoccus palustris & плоды & RG [100] \\
\hline \multicolumn{3}{|c|}{ Eucommiaceae } \\
\hline Eucommia ulmoides & кора & AGP, RG $[101,102]$ \\
\hline \multicolumn{3}{|c|}{ Fabaceae } \\
\hline Amorpha fruticosa & плоды & Ga-Mn [103] \\
\hline Cassia acutifolia & лист & $\mathrm{RG}, \mathrm{AG}[104]$ \\
\hline & плоды & Ga-Mn [105] \\
\hline Glycyrrhiza glabra & корни & ${ }^{\text {ws }}$ Rha, Ara, (Gl) [106] \\
\hline Glycyrrhiza uralensis & корни & $\mathrm{Ar}, \mathrm{AG}, \mathrm{Ga}, \mathrm{Gl}, \mathrm{GU}, \mathrm{RG}$ [107-110] \\
\hline Melilotus officinalis & трава & RG [99] \\
\hline Mimosa pudica & лист & $\mathrm{AG}, \mathrm{RG}[111]$ \\
\hline Phaseolus vulgaris & створки & GU, AG [112] \\
\hline Styphnolobium japonicum & плоды & Ga-Mn [113] \\
\hline Trigonella foenum-graecum & семя & Ga-Mn [114] \\
\hline \multicolumn{3}{|c|}{ Ginkgoaceae } \\
\hline Ginkgo biloba & лист & Ga, Rh-Ga-Mn [18] \\
\hline \multicolumn{3}{|c|}{ Grossulariaceae } \\
\hline Ribes nigrum & плоды & AG, RG [115] \\
\hline
\end{tabular}


Продолжение таблищь 5

\begin{tabular}{|c|c|c|}
\hline 1 & 2 & 3 \\
\hline \multicolumn{3}{|c|}{ Hymenochaetaceae } \\
\hline Inonotus obliquus & склероции & Gl, Ga $\alpha-1,3-G l, \beta-1,3-G 1$ [116-118] \\
\hline \multicolumn{3}{|c|}{ Hypericaceae } \\
\hline Hypericum perforatum & трава & RG [119] \\
\hline \multicolumn{3}{|c|}{ Iridaceae } \\
\hline Iris pseudacorus & корни & ${ }^{\mathrm{WS}} \mathrm{Gal},{ }^{\mathrm{PS}} \mathrm{UA} 76.7 \%, \mathrm{Gal},{ }^{\mathrm{HCA}} \mathrm{Gal}, \mathrm{Xyl},{ }^{\mathrm{HCB}} \mathrm{Gal}$, Glc [120] \\
\hline \multicolumn{3}{|r|}{ Lamiaceae } \\
\hline Mentha $\times$ piperita & лист & Xl-Gl, RG, AG, $\alpha-4,6-G l$, Ga, AGP, GU[121-124] \\
\hline Origanum vulgare & трава & $\alpha-4,6-\mathrm{Gl}, \mathrm{AG}, \mathrm{GU}[125]$ \\
\hline Salvia officinalis & лист & AG, GlA-Xl, GU, RG, Gl-Mn [126-128] \\
\hline Scutellaria baicalensis & корни & $\alpha-4,6-\mathrm{Gl}[129]$ \\
\hline Thymus vulgaris & трава & AG, AGP, RG $[130,131]$ \\
\hline \multicolumn{3}{|c|}{ Laminariaceae } \\
\hline Laminaria japonica, L. saccharina & слоевища & $\begin{array}{c}\beta-\mathrm{Gl} \text { (ламинаран), Fu (фукоиндан), MnA-GuA (альгиновая } \\
\text { кислота) [132] }\end{array}$ \\
\hline \multicolumn{3}{|r|}{ Linaceae } \\
\hline Linum ussitatissimum & семя & Ar-Xl, Ga, RGI [133-135] \\
\hline \multicolumn{3}{|c|}{ Loganiaceae } \\
\hline Strychnos nux-vomica & семя & Ga, Ga-Mn [136, 137] \\
\hline \multicolumn{3}{|c|}{ Malvaceae } \\
\hline Althaea officinalis & корни & $\alpha-4,6-G l$, GlA-Xl, Ar [138-141] \\
\hline Althaea armeniaca & корни & $\alpha-4,6-G 1[142]$ \\
\hline \multicolumn{3}{|c|}{ Menyanthaceae } \\
\hline Menyanthes trifoliata & лист & ${ }^{\text {WS }}$ Gal, Ara [143] \\
\hline \multicolumn{3}{|c|}{ Orchidaceae } \\
\hline Orchis morio & клубни & Gl-Mn [144] \\
\hline \multicolumn{3}{|r|}{ Papaveraceae } \\
\hline Chelidonium majus & трава & $\begin{array}{c}\text { GlyPr, белок 28,2\%, углеводы } 69,8 \% \text { (Gal : Man : Glc } 5: 4: 1) \\
{[145]}\end{array}$ \\
\hline Papaver somniferum & короб. & GU, GIU [146] \\
\hline \multicolumn{3}{|c|}{ Parmeliaceae } \\
\hline $\begin{array}{c}\text { Cetraria cucullata, } \text { C. islandica, } \\
\text { C. nivalis }\end{array}$ & слоев. & $\beta-3,4-\mathrm{Gl}$ (лихенан), $\alpha-3,4-\mathrm{Gl}$ (изолихенан), Mn [33] \\
\hline \multicolumn{3}{|c|}{ Peganaceae } \\
\hline Peganum harmala & трава & AG, RG [147] \\
\hline \multicolumn{3}{|c|}{ Pinaceae } \\
\hline Abies sibirica & хвоя & RG [99] \\
\hline \multicolumn{3}{|c|}{ Plantaginaceae } \\
\hline Plantago major & лист & AG, RG, Gl-Mn [148-150] \\
\hline Plantago psyllium & семя & Ar-Xl, Xl, RG [151, 152] \\
\hline \multicolumn{3}{|c|}{ Polygonaceae } \\
\hline $\begin{array}{c}\text { Polygonum aviculare, } P . \\
\text { hydropiper }\end{array}$ & трава & ${ }^{\mathrm{WS}}$ Glc, Gal, Ara [153] \\
\hline \multicolumn{3}{|c|}{ Primulaceae } \\
\hline Primula veris & лист & AG, RG [154] \\
\hline \multicolumn{3}{|c|}{ Ranunculaceae } \\
\hline Adonis vernalis & трава & ${ }^{\mathrm{WS}}$ UA $36 \%$, Glc [155] \\
\hline \multicolumn{3}{|c|}{ Rosaceae } \\
\hline Aronia melanocarpa & плоды & ${ }^{\text {WS }}$ GalA 84-90\% [156] \\
\hline Crataegus spp. & плоды & ${ }^{\text {WS }}$ GalA $40-44 \%$, Ara, ${ }^{\text {PS }}$ GalA $40-52 \%{ }^{*}$ [157] \\
\hline Filipendula ulmaria & цветки & ${ }^{\text {WS }}$ UA 55,9\%, Gal, Ara [99] \\
\hline Fragaria vesca & лист & ${ }^{\text {WS }}$ UA $53 \%$, Gal, Rha [158] \\
\hline Rosa spp. & плоды & ${ }^{\mathrm{WS}} \mathrm{Glc},{ }^{\mathrm{PS}} \mathrm{GalA}^{* *}[159]$ \\
\hline Sanguisorba officinalis & корни & AG $[160]$ \\
\hline Sorbus aucuparia & плоды & RG [161] \\
\hline
\end{tabular}

\footnotetext{
* Приведены данные для Crataegus orientalis.

** Приведены данные для Rosa canina.
} 
Окончание таблиць 5

\begin{tabular}{|c|c|c|}
\hline 1 & 2 & 3 \\
\hline \multicolumn{3}{|c|}{ Rutaceae } \\
\hline Phellodendron amurense & лист & RGII, AG [162] \\
\hline Ruta graveolens & трава & Xl-Gl [163] \\
\hline \multicolumn{3}{|c|}{ Saxifragaceae } \\
\hline Bergenia crassifolia & лист & RGI [164] \\
\hline \multicolumn{3}{|c|}{ Solanaceae } \\
\hline Capsicum аппиит & плоды & RG [165] \\
\hline \multicolumn{3}{|c|}{ Tiliaceae } \\
\hline Tilia cordata & цветки & ${ }^{\mathrm{WS}}$ UA $40-45 \%$, Gal [166] \\
\hline \multicolumn{3}{|c|}{ Urticaceae } \\
\hline Urtica dioica & лист & Gl, AG, RG [167] \\
\hline \multicolumn{3}{|c|}{ Usneaceae } \\
\hline Usnea barbata U. longissima & слоевища & $\beta-3,4-\mathrm{Gl}$ (лихенан), $\alpha-3,4-\mathrm{Gl}$ (изолихенан) [33] \\
\hline \multicolumn{3}{|c|}{ Valerianaceae } \\
\hline Valeriana officinalis & корни & AG [168] \\
\hline \multicolumn{3}{|c|}{ Viburnaceae } \\
\hline Viburnum opulus & плоды & GU, AG [169] \\
\hline \multicolumn{3}{|c|}{ Violaceae } \\
\hline Viola tricolor & трава & ${ }^{\mathrm{WS}} \mathrm{Glc}, \mathrm{Gal},{ }^{\text {PS }} \mathrm{GalA}, \mathrm{Glc}, \mathrm{Gal}[170]$ \\
\hline \multicolumn{3}{|c|}{ Viscaceae } \\
\hline Viscum album & побеги & $\mathrm{AG}, \mathrm{RG}[171]$ \\
\hline \multicolumn{3}{|c|}{ Zygophyllaceae } \\
\hline Tribulus terrestris & трава & AG, RG [172, 173] \\
\hline
\end{tabular}

Примечания. * AG - арабиногалактан; AGP - арабиногалактан-протеиновый комплекс; $\mathrm{Ar}$ - арабинан; $\mathrm{Ar}-\mathrm{Xl}$ - арабиноксилан; Fu - фукан; Fu-Ga-Xl-Gl - фукогалактоксилоглюкан; Ga - галактан; Ga-Mn - галактоманнан; Gl - глюкан; Gl-Fr - глюкофруктаны; Gl-Ga-Mn - глюкогалактоманнан; Gl-Mn - глюкоманнан; Gl-Mn-Ga - глюкоманногалактан; GlA-Xl - глюкуроноксилан; GlA-Ar-Xl - глюкуроноарабиноксилан; GlU - гомоглюкуронан; GU - гомогалактуронан; GlyPr - гликопротеин; HCA - гемицеллюлозы группы A; HCB - гемицеллюлозы группы B; HW - водорастворимые полисахариды, экстрагируемые горячей водой; Mn - маннан; MnA-GuA - мануроно-гулуронан; PS - пектиновые вещества; Rh-AG - рамноарабиногалактан; Rh-Ga-Mn - рамногалактоманнан; RG - рамногалактуронан; RGI - рамногалактуронан I типа; RGII - рамногалактуронан II типа; WS - водорастворимые полисахариды; Xl - ксилан; Xl-Gl - ксилоглюкан; UA - уроновые кислоты.

Учитывая недостаточную степень изученности углеводных полимеров компонентов официнальных растительных видов, мы провели скриниговое изучение водорастворимых полисахаридов (ВРПС) 84 видов, 56 из которых исследовались впервые. Методология анализа включала количественный анализ в сырье, выделение суммарной фракции ВРПС, хроматографическое разделение, определение моносахаридного состава, спектров ИК и ${ }^{13} \mathrm{C}$-ЯМР и последующее отнесение к определенным полисахаридным группам (табл. 6).

В результате установлено, что содержание ВРПС в исследованных видах составляет от 0,7 (цветки Sambucus nigra) до 16\% (корни Rhaponticum carthamoides). Ряд видов можно отнести к накопителям данной группы соединений, в том числе Rhaponticum carthamoides (12-16\%), Schisandra chinensis (8,4-8,7\%), Valeriana officinalis (8,3-8,6\%), Sanguisorba officinalis (6,8-6,9\%), Eleutherococcus senticosus (6,4-7,2\%), Centaurea cyanus (6,1-6,5\%), Helichrysum arenarium (6,0-6,5\%), Cassia acutifolia (6,0-6,1\%).

Впервые установлено присутствие фруктанов в Rhaponticum carthamoides и Tussilago farfara, маннанов в Pastinaca sativa, Pimpinella anisum, Kalanchoe pinnata, Vaccinium myrtillus и V. vitis-idaea. Следует отметить относительно высокую встречаемость арабиногалактан-протеиновых комплексов в видах семейства Lamiaceae, что позволяет ожидать от ВРПС высокой иммуностимулирующей активности. К числу наиболее распространенных групп полисахаридов относятся глюканы и рамногалактуронаны, обнаруженные в 58 и 42 видах соответственно.

Полученные данные, а также сведения литературы о биологической активности полимерных компонентов некоторых видов растительного сырья позволяют пересмотреть их стандартизацию, включив показатель содержания ВРПС в качестве дополнительного количественного параметра к существующим показателям. 
Таблица 6. Содержание и групповая принадлежность водорастворимых полисахаридов некоторых официнальных растительных видов

\begin{tabular}{|c|c|c|c|c|c|c|c|c|}
\hline \multirow{2}{*}{ Вид } & \multirow{2}{*}{$\begin{array}{c}\text { Морфологическая } \\
\text { группа }\end{array}$} & \multirow{2}{*}{ ВРПС, \% } & \multicolumn{6}{|c|}{ Группа полисахаридов* } \\
\hline & & & Gl & $\mathrm{Mn}$ & Fr & $\mathrm{AG}$ & AGP & $\mathrm{RG}$ \\
\hline 1 & 2 & 3 & 4 & 5 & 6 & 7 & 8 & 9 \\
\hline \multicolumn{9}{|c|}{ Amaranthaceae } \\
\hline Aerva lanata & трава & $1,4-1,7$ & + & & & & & \\
\hline \multicolumn{9}{|c|}{ Araceae } \\
\hline Acorus calamus & корни & $2,7-3,8$ & + & & & & & \\
\hline \multicolumn{9}{|c|}{ Araliaceae } \\
\hline Aralia elata & корни & $5,4-6,1$ & + & & & & & \\
\hline Eleutherococcus senticosus & корни & $6,4-7,2$ & + & & & & & \\
\hline \multicolumn{9}{|c|}{ Apiaceae } \\
\hline Carum carvi & плоды & $0,8-1,2$ & + & & & & & \\
\hline Pastinaca sativa** & плоды & $1,4-2,4$ & & + & & & & \\
\hline Peucedanum morisonii*** & корни & $1,5-1,8$ & + & & & & & \\
\hline Pimpinella anisum** & плоды & $1,3-1,8$ & & + & & & & \\
\hline Phlojodicarpus sibiricus** & корни & $1,9-2,1$ & + & & & & & \\
\hline \multicolumn{9}{|c|}{ Asteraceae } \\
\hline Achillea millefolium & трава & $1,7-1,9$ & & & & + & & + \\
\hline Arnica montana & цветки & $1,7-1,9$ & + & & & & & + \\
\hline Artemisia absinthium** & трава & $3,2-3,5$ & & & & & + & + \\
\hline Artemisia vulgaris** & трава & $2,2-2,6$ & & & & & & + \\
\hline Bidens tripartita** & трава & $2,0-2,2$ & & & & & + & + \\
\hline Calendula officinalis & цветки & $5,2-5,7$ & + & & & & & \\
\hline Centaurea cyanus & цветки & $6,1-6,5$ & + & & & + & & \\
\hline Echinops ritro** & плоды & $3,3-3,7$ & & & & + & & + \\
\hline Helichrysum arenarium** & цветки & $6,0-6,5$ & & & & & & + \\
\hline Gnaphalium uliginosum** & трава & $3,2-3,5$ & & & & & + & + \\
\hline Rhaponticum carthamoides $* *$ & корни & $12-16^{* * *}$ & & & + & & & \\
\hline Silybum marianum** & плоды & $1,0-1,2$ & & & & & & + \\
\hline Tussilago farfara & лист & $3,4-3,8 * * *$ & + & & + & & & \\
\hline \multicolumn{9}{|c|}{ Berberidaceae } \\
\hline Berberis vulgaris & плоды & $4,6-5,8$ & & & & & & + \\
\hline \multicolumn{9}{|c|}{ Betulaceae } \\
\hline Alnus incana** & соплодия & $2,0-2,1$ & + & & & & & \\
\hline & почки & $1,7-1,9$ & + & & & & & + \\
\hline веtula pendula & лист & $2,2-2,4$ & + & & & & & \\
\hline \multicolumn{9}{|c|}{ Brassicaceae } \\
\hline Capsella bursa-pastoris ${ }^{* *}$ & трава & $2,1-2,4$ & & & & & & + \\
\hline \multicolumn{9}{|c|}{ Crassulaceae } \\
\hline Kalanchoe pinnata** & побеги & $5,7-8,4$ & & + & & & & + \\
\hline Rhodiola rosea** & корни & $5,5-5,7$ & + & & & & & + \\
\hline Sedum maximum ${ }^{* *}$ & трава & $2,1-2,7$ & + & & & & & \\
\hline \multicolumn{9}{|c|}{ Cupressaceae } \\
\hline Juniperus communis** & плоды & $0,9-1,5$ & & & & & & + \\
\hline \multicolumn{9}{|c|}{ Dioscoreaceae } \\
\hline Dioscorea nipponica** & корни & $3,7-3,9$ & + & & & & & \\
\hline \multicolumn{9}{|c|}{ Elaeagnaceae } \\
\hline Hippophae rhamnoides & плоды & $5,9-6,6$ & + & & & & & + \\
\hline \multicolumn{9}{|c|}{ Equisetaceae } \\
\hline Equisetum arvense ${ }^{* *}$ & трава & $1,4-1,5$ & + & & & & & \\
\hline \multicolumn{9}{|c|}{ Ericaceae } \\
\hline Ledum palustre & побеги & $2,5-2,8$ & + & & & & & \\
\hline Vaccinium myrtillus** & побеги & $2,1-2,4$ & & + & & & & + \\
\hline Vaccinium vitis-idaea** & лист & $3,1-3,4$ & & + & & & & + \\
\hline
\end{tabular}


Продолжение таблищы 6

\begin{tabular}{|c|c|c|c|c|c|c|c|c|}
\hline 1 & 2 & 3 & 4 & 5 & 6 & 7 & 8 & 9 \\
\hline \multicolumn{9}{|c|}{ Fabaceae } \\
\hline Cassia acutifolia & лист & $6,0-6,1$ & + & & & & \multirow{7}{*}{+} & \\
\hline Lespedeza bicolor** & побеги & $2,6-2,8$ & + & & & & & + \\
\hline Lespedeza hedysaroides** & трава & $3,1-3,3$ & + & & & & & + \\
\hline Melilotus officinalis & трава & $2,4-2,5$ & + & & & & & \\
\hline Ononis arvensis** & корни & $5,7-5,8$ & + & & & & & \\
\hline Phaseolus vulgaris & створки & $3,5-3,7$ & + & & & & & \\
\hline Thermopsis lanceolata** & трава & $2,6-2,9$ & & & & + & & + \\
\hline \multicolumn{9}{|c|}{ Fagaceae } \\
\hline Quercus robur** & кора & $1,4-1,6$ & + & & & & & + \\
\hline \multicolumn{9}{|c|}{ Hippocastanaceae } \\
\hline Aesculus hippocastamun** & семя & $3,0-3,6$ & + & & & & & \\
\hline \multicolumn{9}{|c|}{ Hypericaceae } \\
\hline Hypericum perforatum & трава & $2,9-3,3$ & + & & & & & \\
\hline \multicolumn{9}{|c|}{ Lamiaceae } \\
\hline Leonurus cardiaca** & трава & $0,8-1,2$ & + & & & & + & + \\
\hline Leonurus quinquelobatus** & трава & $0,9-1,2$ & + & & & & + & + \\
\hline Melissa officinalis** & трава & $5,6-6,3$ & + & & & & + & + \\
\hline Orthosiphon stamineus** & лист & $1,5-1,7$ & + & & & & + & + \\
\hline Stachys betoniciflora** & трава & $1,8-2,0$ & + & & & & + & + \\
\hline Thymus serpyllum** & трава & $2,2-2,5$ & + & & & & + & + \\
\hline \multicolumn{9}{|c|}{ Myrtaceae } \\
\hline Eucalyptus viminalis** & лист & $2,0-2,3$ & & & & & & + \\
\hline \multicolumn{9}{|c|}{ Nymphaeaceae } \\
\hline Nuphar lutea** & корни & $4,9-5,3$ & + & & & & & + \\
\hline \multicolumn{9}{|c|}{ Paeoniaceae } \\
\hline Paeonia anomala** & корни & $2,8-3,3$ & + & & & & & \\
\hline \multicolumn{9}{|c|}{ Papaveraceae } \\
\hline Chelidonium majus & трава & $2,4-2,6$ & + & & & & & \\
\hline \multicolumn{9}{|c|}{ Pinaceae } \\
\hline Pinus sylvestris** & почки & $1,2-1,5$ & & & & & & + \\
\hline \multicolumn{9}{|c|}{ Poaceae } \\
\hline Zea mays** & столбики & $3,0-3,3$ & 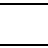 & & & & & + \\
\hline \multicolumn{9}{|c|}{ Polygonaceae } \\
\hline Bistorta major** & корни & $5,1-5,3$ & + & & & & & + \\
\hline Polygonum hydropiper & трава & $2,6-2,7$ & + & & & & & \\
\hline Polygonum persicaria** & трава & $4,3-4,6$ & + & & & & & \\
\hline Rheum palmatum** & корни & $4,9-5,7$ & + & & & & & \\
\hline Rumex confertus** & корни & $3,7-4,2$ & + & & & & & \\
\hline \multicolumn{9}{|c|}{ Ranunculaceae } \\
\hline Aconitum soongaricum** & клубни & $4,6-5,2$ & + & & & & & \\
\hline Helleborus purpurascens $* *$ & корни & $3,9-4,0$ & + & & & & & \\
\hline \multicolumn{9}{|c|}{ Rhamnaceae } \\
\hline Frangula alnus ${ }^{* *}$ & кора & $5,7-5,9$ & + & & & & & \\
\hline Rhamnus cathartica** & плоды & $7,1-7,3$ & + & & & & & \\
\hline \multicolumn{9}{|c|}{ Rosaceae } \\
\hline Filipendula ulmaria & цветки & $3,0-3,5$ & + & & & & & + \\
\hline Fragaria vesca & лист & $2,7-2,9$ & & & & & & + \\
\hline Potentilla erecta** & корни & $2,5-2,6$ & + & & & & & + \\
\hline Rubus idaeus** & плоды & $3,1-3,6$ & & & & & & + \\
\hline Sanguisorba officinalis & корни & $6,8-6,9$ & + & & & & & \\
\hline & & ubiaceae & & & & & & \\
\hline Rubia tinctorum** & корни & $2,1-2,2$ & + & & & & & \\
\hline & & nbucaceae & & & & & & \\
\hline Sambucus nigra** & цветки & $0,7-1,5$ & + & & & & & \\
\hline & & ifragaceae & & & & & & \\
\hline Bergenia crassifolia** & корни & $5,6-6,2$ & + & & & & & \\
\hline
\end{tabular}


Окончание таблиць 6

\begin{tabular}{|c|c|c|c|c|c|c|c|c|}
\hline 1 & 2 & 3 & 4 & 5 & 6 & 7 & 8 & 9 \\
\hline \multicolumn{9}{|c|}{ Scrophulariaceae } \\
\hline Digitalis lanata** & лист & $4,3-4,4$ & & & & & & + \\
\hline Digitalis purpurea** & лист & $5,5-5,9$ & + & & & & & \\
\hline \multicolumn{9}{|c|}{ Schisandraceae } \\
\hline Schisandra chinensis ${ }^{* *}$ & плоды & $8,4-8,7$ & & & & & & + \\
\hline \multicolumn{9}{|c|}{ Solanaceae } \\
\hline Capsicum аппиит & плоды & $3,7-3,9$ & + & & & & & \\
\hline \multicolumn{9}{|c|}{ Tiliaceae } \\
\hline Tilia cordata & цветки & $4,5-4,7$ & & & & & + & + \\
\hline \multicolumn{9}{|c|}{ Valerianaceae } \\
\hline Valeriana officinalis & корни & $8,3-8,6$ & + & & & & & \\
\hline \multicolumn{9}{|c|}{ Violaceae } \\
\hline Viola tricolor & трава & $5,5-5,8$ & + & & & & & + \\
\hline \multicolumn{9}{|c|}{ Viscaceae } \\
\hline Viscum album & побеги & $2,1-2,3$ & + & & & & & \\
\hline \multicolumn{9}{|c|}{ Zygophyllaceae } \\
\hline Tribulus terrestris & трава & $2,1-2,5$ & + & & & & & \\
\hline
\end{tabular}

Примечание. * обозначения сокращений см. в табл. 5; ** растительные виды, впервые исследованные на содержание полисахаридов; *** суммарное содержание фруктанов.

Распределение классов полисахаридов по морфологическим группам растительных видов. Обобщая полученные данные о составе полисахаридов в изученных растительных видах, а также сведения литературы, можно предположить о существовании общих химических особенностей в накоплении данных соединений в различных морфологических группах, что обусловлено прежде всего биологическим значением различных органов в жизни растения, а также биохимическими свойствами метаболизма. Анализ химической информации показал, что существует три категории полисахаридных классов, присутствие которых в данной морфологической группе является обязательнылм, частылм или редким.

В частности, для стеблей, выполняющих опорную функцию, помимо целлюлозы, характерно доминирование ПС-групп, формирующих группу гемицеллюлоз (ксиланы, глюкуронаны и др.) - водонерастворимых компонентов, комплексы которых с растительным лигнином обладают высокими прочностными характеристиками. Содержание водорастворимых полисахаридов и пектиновых веществ для стеблей, как правило, невелико, хотя существуют и исключения, например представители сем. Malvaceae.

Доминирующими классами полисахаридов листьев являются галактуронаны (RG, HGU) и различные типы арабиногалактанов. Содержание полисахаридных комплексов в листьях растительных видов может составлять до 10-40\%, однако следует отметить, что наибольшая часть приходится на минеральную составляющую (до 80\% от массы ВРПС). Более того, частым сопутствующим компонентом являются фенол-углеводные комплексы, представляющие собой ацилированные формы нейтральных полисахаридов типа глюканов, галактанов или арабинанов.

Цветки представляют собой репродуктивный орган, ответственный за размножение растительного вида, время жизни которого относительно невелико. Для нормального фунционирования цветка необходимо большое количество энергии, получаемой из легкогидролизуемых групп ПС (глюканы, фруктаны) и высокий иммунный статус, за наличие которого отвечают компоненты пектинового комплекса (галактуронаны и арабиногалактаны). Значительное содержание галактуронанов, особенно в водорастворимой форме, объясняется необходимостью поддержания тургора цветка, так как он испытывает механическое воздействие во время процесса опыления. Суммарная концентрация биодоступных полисахаридов (ВРПС, ПВ) может составлять до 20-30\% от массы цветка (до 50-70\% от массы экстрактивных веществ).

Семя является хранителем генетической информации о виде, для прорастания которого необходимо огромное количество энергии, получаемой из легкогидролизуемых водорастворимых групп полисахаридов запасного типа - глюканов типа крахмала, галакто- и/или глюкоманнанов; содержание подобных соединений в семенах может составлять до 40-50\%.

Одной из основных функций подземных органов, кроме осуществления водного и минерального питания, является запасание питательных веществ при переходе растения в период покоя. Гиперконцентрация в корнях (корневищах, клубнях, луковицах) ряда полисахаридов типа крахмала, инулина, глюкоманнанов объясняется прежде всего тем, что при возобновлении роста растительного организма весной ему потребуют- 
ся энергетические источники в виде биодоступных моно- и олигосахаридов. Для некоторых растительных видов содержание водорастворимых полисахаридов в подземных органах может составлять до 50-65\%.

В таблице 7 приведены общие данные о распространении и содержании различных полисахаридных классов в морфологических группах растений. Данная информация может быть полезной при априорной оценке состава и содержания полисахаридов в растении.

В заключение следует отметить, что, несмотря на необходимость проведения фундаментальных научных исследований в области изучения структуры и биологической активности природных биополимеров, актуальной остается задача использования лекарственных средств, содержащих данные соединения. Анализ имеющейся номенклатуры лекарств, разрешенных к применению в официнальной практике, свидетельствует о том, что ассортимент полисахарид-содержащих препаратов ограничен, в связи с чем необходимыми являются исследования по созданию лекарственных средств с использованием рациональных технологий производства, а также разработка современных методов стандартизации подобных препаратов.

Таблица 7. Распределение классов полисахаридов в морфологических группах растительных видов*

\begin{tabular}{|c|c|c|c|}
\hline \multirow{2}{*}{$\begin{array}{c}\text { Морфологическая } \\
\text { группа }\end{array}$} & \multicolumn{3}{|c|}{ Полисахаридные классы, их встречаемость и содержание, \% } \\
\hline & Постоянные компоненты & Часто встречаемые компоненты & Редкие компоненты \\
\hline Цветки & $\begin{array}{l}\text { RG, GU (6-15) } \\
\text { AG, AGP (4-6) }\end{array}$ & $\begin{array}{l}\mathrm{Gl}(1-3) \\
\mathrm{Ga}(1-2) \\
\mathrm{Ar}(1-2)\end{array}$ & $\operatorname{Fr}(1-4)$ \\
\hline Семена & $\begin{array}{c}\text { Gl (5-40) } \\
\text { RG, GU (1-3) } \\
\text { AG, AGP (1-2) }\end{array}$ & $\begin{array}{l}\text { Ga-Mn (1-40) } \\
\text { Gl-Mn (1-30) }\end{array}$ & $\begin{array}{c}\mathrm{Ar}-\mathrm{Xl}(4-20) \\
\mathrm{Ar}(1-2) \\
\mathrm{Xl}(1-4)\end{array}$ \\
\hline Листья & $\begin{array}{l}\text { RG, GU (3-12) } \\
\text { AG, AGP (1-5) } \\
\quad \text { Gl (1-3) }\end{array}$ & $\begin{array}{l}\operatorname{Fr}(1-2) \\
\operatorname{Ga}(1-2) \\
\operatorname{Ar}(1-2)\end{array}$ & $\begin{array}{l}\mathrm{Xl}(1-4) \\
\operatorname{Mn}(1-3) \\
\operatorname{Ra}(1-2)\end{array}$ \\
\hline Стебли & $\begin{array}{c}\text { Xl (5-15) } \\
\text { Gl (2-8) } \\
\text { GlU (3-8) }\end{array}$ & $\begin{array}{c}\mathrm{Ga}(1-2) \\
\mathrm{Ar}(1-2) \\
\mathrm{RG}, \mathrm{GU}(2-4)\end{array}$ & $\begin{array}{l}\text { AG, AGP (1-2) } \\
\text { Mn }(1-3) \\
\text { Ra }(1-3)\end{array}$ \\
\hline Корни & $\begin{array}{c}\text { Gl (5-50) } \\
\text { RG, GU (2-5) } \\
\text { AG, AGP (1-2) }\end{array}$ & $\begin{array}{c}\text { Fr }(5-50) \\
\text { Gl-Mn }(5-40) \\
\text { Ga }(1-5) \\
\text { Ar }(1-5)\end{array}$ & $\begin{array}{l}\mathrm{Xl}(1-3) \\
\mathrm{Ra}(1-2)\end{array}$ \\
\hline
\end{tabular}

Примечание. * обозначения сокращений см. в таблице 5.

\section{Экспериментальная часть}

Растительное сырье. Сырье для исследований было собрано в разных районах СНГ, любезно предоставлено рядом зарубежных компаний, а также приобретено через аптечную и торговую сети: Бурятия, окр. Улан-Удэ - Acorus calamus (п. Исток), Artemisia vulgaris (п. Вахмистрово), Carum carvi, Chelidonium majus, Hippophae rhamnoides, Leonurus cardiaca, Phaseolus vulgaris, Pimpinella anisum, Rhodiola rosea, Tribulus terrestris, Zea mays (Улан-Удэ, ст. Тальцы); Заиграевский р-он - Achillea millefolium, Echinops ritro L. (син. E. ruthenicus) (п. Онохой); Paeonia anomala (д. Цакир) - Polygonum persicaria (син. Persicaria maculata) (с. Эрхирик); Прибайкальский р-он - Bidens tripartite, Calendula officinalis, Capsella bursapastoris, Centaurea cyanus, Ledum palustre, Pinus sylvestris, Sanguisorba officinalis, Tussilago farfara, Vaccinium vitis-idaea, Valeriana officinalis (п. Горячинск), Bergenia crassifolia, Vaccinium myrtillus (Пыхта); Мухоршибирский р-он - Sedum maximum (син. Hylotelephium maximum) (с. Мухоршибирь), Melilotus officinalis, Stachys betoniciflora (с. Заган), Rubus idaeus (c. Бар); Кабанский р-он - Juniperus communis (ст. Мысовая), Bistorta major, Polygonum hydropiper (син. Persicaria hydropiper) (д. Истомино); Джидинский p-он - Lespedeza hedysaroides (син. L. Juncea) (с. Нарын); Селенгинский р-он - Thermopsis lanceolata (д. Нижний Убукун); Тарбагатайский р-он - Filipendula ulmaria, Fragaria vesca (с. Никольское); Иркутская обл - Kalanchoe pinnata (Иркутск, Оранжерея СИФИБР СО РАН); Московская обл. - Ononis arvensis (Mосква, ГБС СО РАН), Nuphar lutea, Rheum palmatum, Thymus serpyllum (Москва, ВИЛАР); Ленинградская обл. - Digitalis lanata, D. purpurea (окр. п. Лемблово); Алтайский край - Melissa officinalis, Rumex confertus (с. Родино); Приморский край - Lespedeza bicolor; Авентин, Фирма - Frangula alnus; Алекс, ООО - Betula pendula; Аптека Центра восточной медицины, ООО - Rubia tinctorium, Viola tricolor; Даурская заготовительная компания, ООО - Aralia elata, Berberis vulgaris, Eleutherococcus senticosus, Stemmacantha carthamoides; Здоровье, ЗАО - Sambucus nigra; Красногорсклексредства, ЗАО - Eucalyptus viminalis, 
Leonurus quinquelobatus, Potentilla erecta, Tilia cordata; Кубань-фарммед, ЗАО - Rhamnus cathartica, Viscum album; Лекс+, ООО - Cassia acutifolia, Quercus robur, Silybum marianum, Hypericum perforatum; Ленмедснаб-Доктор W, ЗАО - Gnaphalium uliginosum (син. Filaginella uliginoza); Медал, ООО - Aerva lanata; Охота, ООО - Pеисеdanum morisonii, Phlojodicarpus sibiricus; СТ Медифарм, 3АО - Equisetum arvense, Helichrysum arenarium; Подбаза, ООО - Cарsicum аппит; Техмедсервис, ЗАО - Alnus incana, Arnica montana; ФитоЭМ, Фирма - Artemisia absinthium; Padma AG, Фирма - Aesculus hippocastanum, Aconitum soongaricum, Dioscorea nipponica (Швейцария, Шверценбах); Trisco Со., Компания - Orthosiphon stamineus (Индонезия).

Общие экспериментальные условия. Спектрофотометрические исследования проводили на спектрофотометре СФ-2000 (ОКБ Спектр). ИК-спектры регистрировали на ИК-Фурье спектрометре ФТ-801 (Симекс) в интервале 4000-600 см ${ }^{-1}$ в пленке на ZnSe-окнах-подложках. Спектры ${ }^{13} \mathrm{C}-Я М Р$ регистрировали на ЯMР-спектрометре VXR 500S (Varian). Суммарное содержание ВРПС определяли антронсернокислотным методом [174], суммарное содержание фруктанов - резорциновым методом [175]. Условия выделения и очиски ВРПС, гидролиза, определение моносахаридного состава (МС), ВЭЖХ анализ гидролизатов описаны нами ранее [176-179]. Определение присутствия разных классов полисахаридов проводили следующим образом: глюканы - положительная реакция с йодом, МС и ИК фракции, полученной после осаждения с йодом [180]; маннаны - осаждение с реактивом Феллинга с последующими регенерацией, МС и ИК [181]; фруктаны - положительная резорциновая реакция, выделение фракции нейтральных полисахаридов на ДЭАЭ-целлюлозе ( $\mathrm{CO}_{3}{ }^{2-}$-форма), $\mathrm{MC},{ }^{13} \mathrm{C}$-ЯМР [182]; арабиногалактаны - выделение фракции нейтральных полисахаридов на ДЭАЭ-целлюлозе (ОН-фформа), МС, ИК, ${ }^{13} \mathrm{C}-Я М Р$ [183]; арабиногалактан-протеиновые комплексы - положительная реакция с реактивом Yariv [184]; рамногалактуронаны - выделение фракции кислых полисахаридов на ДЭАЭ-целлюлозе (ОН--форма), частичный гидролиз $2 \% \mathrm{H}_{2} \mathrm{SO}_{4}$, выделение негидролизованного остатка, МС, ИК, ${ }^{13} \mathrm{C}$-ЯМР [70].

\section{Список литературы}

1. Baker J.L., Pope T.H. // J. Chem. Soc. Trans. 1990. Vol. 77. Pp. 696-705.

2. Dubois M., Gilles K.A., Hamilton J.K., Rebers P.A., Smith F. // Anal. Chem. 1956. Vol. 28. Pp. 350-356.

3. Van Soest P.J., Robertson J.B., Lewis B.A. // J. Dairy Sci. 1991. Vol. 74. Pp. 3583-3597.

4. Carpita N.C., Gibeaut D.M. // Plant J. 1993. Vol. 3. Pp. 1-30.

5. Schleifer K.H., Kandler O. // Bacteriol. Rev. 1972. Vol. 36. Pp. 407-477.

6. Raetz C.R.H., Whitfield C. // Ann. Rev. Biochem. 1992. Vol. 71. Pp. 635-700.

7. Laurent T.C., Fraser J.R.E. // FASEB J. 1992. Vol. 6. Pp. 2397-2404.

8. Ravi Kumar M.N.V. // React. Funct. Polym. 2000. Vol. 46. Pp. 1-27.

9. Helenius A., Aebi M. // Science. 2001. Vol. 291. Pp. 2364-2369.

10. Hakomori S.-I. // J. Biochem. 1964. Vol. 55. Pp. 205-208.

11. Englyst H.N., Kingman S.M., Cummings J.H. // Eur. J. Clin. Nutr. 1992. Vol. 46 (Suppl. 2). Pp. S33-S50.

12. Gibson G.R., Beatty E.R., Wang X., Cummings J.H. // Gastroenterology. 1995. Vol. 108. Pp. 975-982.

13. Stevenson T.T., Furneaux R.H. // Carbohydr. Res. 1991. Vol. 210. Pp. 277-298.

14. Ridley B.L., O'Neill M.A., Mohnen D. // Phytochemistry. 2001. Vol. 57. Pp. 929-967.

15. Rowley J.A., Madlambayan G., Mooney D.J. // Biomaterials. 1999. Vol. 20. Pp. 45-53.

16. Patankar M.S., Oehninger S., Barnett T., Williams R.L., Clark G.F. // J. Biol. Chem. 1993. Vol. 268. Pp. 21770-21776.

17. Wang Y.P. // Chin. J. Modern Develop. Trad. Med. 1991. Vol. 11. Pp. 61-63.

18. He L., Guo-Ying Z., Jian-Ping X., Jun-Ang L., Huai-Yun Z., Yimin T. // J. Med. Plant Res. 2012. Vol. 6. Pp. $171-176$.

19. Sun Y. // Carbohydr. Polym. 2011. Vol. 85. Pp. 490-499.

20. Gupta V., Puri R., Gupta S., Jain S., Rao G.K. // Syst. Rev. Pharm. 2010. Vol. 1. Pp. 50-54.

21. Mathur V., Mathur N.K. // J. Sci. Ind. Res. 2005. Vol. 64. Pp. 475-481.

22. Zhong S., Pan H., Fan L., Lv G., Wu Y., Parmeswaran B., Pandey A., Soccol C.R. // Food Technol. Biotechnol. 2009. Vol. 47. Pp. 304-312.

23. Houseknecht J.B., Lowary T.L. // Curr. Opin. Chem. Biol. 2001. Vol. 5. Pp. 677-682.

24. Щербухин В.Д. // Прикл. биохим. микробиол. 1993. Т. 29. С. 803-813.

25. Щербухин В.Д., Анулов О.В. // Прикл. биохим. микробиол. 1999. Т. 35. С. 257-274.

26. Srivastava M., Kapoor V.P. // Chem. Biodiv. 2005. Vol. 2. Pp. 295-317.

27. Arifkhodzhaev A.O. // Chem. Nat. Comp. 1997. Vol. 33. Pp. 1-10.

28. Paulsen B.S., Barsett H. // Adv. Polym. Sci. 2005. Vol. 186. Pp. 69-101.

29. Yapo B.M. // Carbohydr. Polym. 2011. Vol. 86. Pp. 373-385.

30. Berteau O., Mulloy B. // Glycobiology. 2003. Vol. 13. Pp. 29R-40R.

31. Shibata N., Okawa Y. // Jap. J. Med. Mycol. 2006. Vol. 47. Pp. 179-184.

32. Willför S., Sundberg A., Pranovich A., Holmbom B. // Wood Sci. Technol. 2005. Vol. 39. Pp. 601-617.

33. Olafsdottir E.S., Ingólfsdottir K. // Planta Med. 2001. Vol. 67. Pp. 199-208. 
34. Senni K., Pereira J., Gueniche F., Delbarre-Ladrat C., Sinquin C., Ratiskol J., Godeau G. // Marine Drugs. 2011. Vol. 9. Pp. 1664-1681.

35. Kelly G.S. // Altern. Med. Rev. 1999. Vol. 4. Pp. 96-103.

36. Barclay T., Ginic-Markovic M., Cooper P., Petrovsky N. // J. Excip. Food Chem. 2010. Vol. 1. Pp. $27-50$.

37. Jezequel V. // Cer. Foods World. 1998. Vol. 43. Pp. 361-364.

38. Nio Y., Itakura M., Yano S., Sumi S.-I., Tamura K. // Biotherapy. 2000. Vol. 14. Pp. 849-858.

39. O'Neill M.A., Ishii T., Albersheim P., Darvill A.G. // Ann. Rev. Plant Biol. 2004. Vol. 55. Pp. 109-139.

40. Pérez S., Rodríguez-Carvajal M.A., Doco T. // Biochimie. 2004. Vol. 85. Pp. 109-121.

41. Coviello T., Palleschi A., Grassi M., Matricardi P., Bocchinfuso G., Alhaique F. // Molecules. 2005. Vol. 10. Pp. 6-33.

42. Leung M.Y.K., Liu C., Koon J.C.M., Fung K.P. // Immunol. Lett. 2006. Vol. 105. Pp. 101-114.

43. Paulsen B.S. // Curr. Org. Chem. 2001. Vol. 5. Pp. 939-950.

44. Ramberg J.E., Nelson E.D., Sinnott R.A. // Nutrit. J. 2010. Vol. 9. Art. no. 54.

45. Schepetkin I.A., Quinn M.T. // Int. Immunopharmacol. 2006. Vol. 6. Pp. 317-333.

46. Lin M.-G., Yang Y.-F., Li Y.-H. // Chin. Trad. Herb. Drugs. 2007. Vol. 38. Pp. 949-953.

47. Ma M.-H., Yi Y.-H., Tang H.-F. // Pharm. Care Res. 2004. Vol. 4. Pp. 305-308.

48. Rakhimov D.A., Kondratenko E.S., Khamidkhodzhaev S.A. // Chem. Nat. Comp. 1983. Vol. 19. Pp. 601-602.

49. Ishii S. // Phytochemistry. 1982. Vol. 21. Pp. 778-780.

50. Khodzhaeva M.A., Kondratenko E.S. // Chem. Nat. Comp. 1984. Vol. 20. Pp. 358-359.

51. Redgwell R.J., Selvendran R.R. Structural features of cell-wall polysaccharides of onion Allium cepa // Carbohydr. Res. 1986. Vol. 157. Pp. 183-199.

52. Das N.N., Das A. // Carbohydr. Res. 1978. Vol. 64. Pp. 155-167.

53. Das N.N., Das A., Kumar Mukherjee A. // Carbohydr. Res. 1977. Vol. 56. Pp. 337-349.

54. Khodzhaeva M.A., Ismailov Z.F. // Chem. Nat. Comp. 1979. Vol. 15. Pp. 114-118.

55. Mallabaev A., Rakhimov D.A., Murdakhaev Yu.M. // Chem. Nat. Comp. 1989. Vol. 25. Pp. 369-370.

56. Polyakova N.S., Rakhimov D.A., Kondratenko E.S. // Chem. Nat. Comp. 1984. Vol. 20. Pp. 612-614.

57. Patra S., Maity K.K., Bhunia S.K., Dey B., Das D., Mondal S., Bhunia B. // Carbohydr. Polym. 2010. Vol. 81. Pp. 584-591.

58. Carbik I., Baser K.H.C., Ozel H.Z., Ergun B., Wagner H. // Planta Med. 1990. Vol. 56. Pp. 668.

59. Muller B.M., Rosskopf F., Paper D.H., Kraus J., Franz G. // Pharmazie. 1991. Vol. 46. Pp. 657-663.

60. Козлова Р.Ю., Клочков В.В., Винтер В.Г. // Уч. зап. Казанск. госуд. ун-та. 2007. Т. 149. С. 125-137.

61. Popov S.V., Vinter V.G., Patova O.A., Markov P.A., Nikitina I.R., Ovodova R.G., Popova G.Yu., Ovodov Yu.S. // Biochemistry (Moscow). 2007. Vol. 72. Pp. 778-784.

62. Belska N.V., Guriev A.M., Danilets M.G., Trophimova E.S., Uchasova E.G., Ligatcheva A.A., Belousov M.V., Belsky Y.P. // Int. Immunopharmacol. 2010. Vol. 10. Pp. 933-942.

63. Соловьева Т.Ф., Прудникова Т.И., Оводов Ю.С. // Растит. ресурсы. 1968. Т. 4. С. 497-501.

64. Chen R., Liu Z., Zhao J., Chen R., Meng F., Zhang M., Ge W. // Food Chem. 2011. Vol. 127. Pp. 434-440.

65. Fang J.-N., Proksch A., Wagner H. // Phytochemistry. 1985. Vol. 24. Pp. 2619-2622.

66. Hikino H., Takahashi M., Otake K., Konno C. // J. Nat. Prod. 1986. Vol. 49. Pp. 293-297.

67. Ovodov Yu.S., Shibaeva V.I. // Chem. Nat. Comp. 1969. Vol. 5. Pp. 501.

68. Ovodova R.G., Lapchik V.F., Ovodov Yu.S. // Chem. Nat. Comp. 1975. Vol. 11. Pp. 1-2.

69. Yagi A., Makino K., Nishioka I., Kuchino Y. // Planta Med. 1977. Vol. 31. Pp. 17-20.

70. Olennikov D.N., Nazarova A.V., Rokhin A.V. // Chem. Nat. Comp. 2009. Vol. 45. Pp. 611-614.

71. Zhauynbaeva K.S., Rakhimov D.A., Nigmatullaev A.A. // Chem. Nat. Comp. 2010. Vol. 46. Pp. 783-784.

72. Hopf H., Kandler O. // Phytochemistry. 1977. Vol. 16. Pp. 1715-1717.

73. Saluk-Juszczak J., Pawlaczyk I., Olas B., Kołodziejczyk J., Ponczek M., Nowak P., Tsirigotis-Wołoszczak M. // Int. J. Biol. Macromol. 2010. Vol. 47. Pp. 700-705.

74. Kardošová A., Ebringerová A., Alföldi J., Nosál'ová G., Fraňová S., Hříbalová V. // Int. J. Biol. Macromol. 2003. Vol. 33. Pp. 135-140.

75. Kato Y., Watanabe T. // Biosci. Biotech. Biochem. 1993. Vol. 57. Pp. 1591-1592.

76. Turdumambetov K., Bakirov G.A., Rakhimov D.A. // Chem. Nat. Comp. 2004. Vol. 40. Pp. 211-214.

77. Puhlmann J., Wagner H. // Planta Med. 1989. Vol. 55. Pp. 99.

78. Varljen J., Lipták A., Wagner H. // Phytochemistry. 1989. Vol. 28. Pp. 2379-2383.

79. Garbacki N., Gloaguen V., Damas J., Bodart P., Tits M., Angenot L. // J. Ethnopharmacol. 1999. Vol. 68. Pp. $235-241$.

80. Chamomile: industrial profiles. Eds. R. Franke, H. Schilcher / Medicinal and Aromatic Plants - industrial profiles. Vol. 42. Boca Raton, London, New York, Singapore: Taylor \& Francis, 2005. 280 p.

81. Bacon J.S.D., Edelman J. // Biochem. J. 1951. Vol. 48. Pp. 114-126.

82. Proksch A., Wagner H. // Phytochemistry. 1987. Vol. 26. Pp. 1989-1993.

83. Wagner H., Stuppner H., Schäfer W., Zenk M. // Phytochemistry. 1988. Vol. 27. Pp. 119-126.

84. Luettig B., Steinmuller C., Gifford G.E., Wagner H., Lohmann-Matthes M.-L. // J. Nat. Cancer Inst. 1989. Vol. 81. Pp. 669-675.

85. Bell D.J., Palmer A. // J. Chem. Soc. 1952. Pp. 3741-3744.

86. Polle A.Ya., Ovodova R.G., Chizhov A.O., Shashkov A.S., Ovodov Yu.S. // Biochemistry (Moscow). 2002. Vol. 67. Pp. 1371-1376. 
87. Xie G., Schepetkin I.A., Quinn M.T. // Int. Immunopharmacol. 2007. Vol. 7. Pp. 1639-1650.

88. Ernst M., Chatterton N.J., Harrison P.A. // New Phytol. 1996. Vol. 132. Pp. 63-66.

89. Olennikov D.N., Tankhaeva L.M., Rokhin A.V. // Chem. Nat. Comp. 2009. Vol. 45. Pp. 141-144.

90. Haaland E. // Acta Chem. Scand. 1969. Vol. 23. Pp. 2546-2548.

91. Henderson G.A., Hay G.W. // Carbohydr. Res. 1972. Vol. 23. Pp. 379-398.

92. Martynov E.G., Stroev E.A., Peskov D.D. // Chem. Nat. Comp. 1984. Vol. 20. Pp. 99-100.

93. Makhatadze M., Bostoganashvili A.M., Barbakadze V., Kemertelidze E., Dekanosidze H. // Ann. New York Acad. Sci. 1993. Vol. 685. Pp. 383-385.

94. Tharanathan R.N., Ramadas Bhat U., Murali Krishna G., Paramahans S.V. // Phytochemistry. 1985. Vol. 24. Pp. 2722-2723.

95. Oosterveld A., Voragen A.G.J., Schols H.A. // Carbohydr. Polym. 2002. Vol. 49. Pp. 407-413.

96. Chushenko V.N., Vinnik E.V., Komissarenko N.F., Stupakova E.P., Petukhova T.V., Zinchenko V.V. // Chem. Nat. Comp. 1992. Vol. 28. Pp. 242-243.

97. Wang G., Liang Z., Zhang L. // Chin. Pharm. J. 1999. Vol. 34. Pp. 229-231.

98. Olennikov D.N., Nazarova A.V. // Chem. Nat. Comp. 2009. Vol. 45. Pp. 702-703.

99. Оводов Ю.С., Головченко В.В., Гюнтер Е.А., Попов С.В. Пектиновые вещества растений европейского севера России. Екатеринбург, 2009. 112 с.

100. Popov S.V., Markov P.A., Nikitina I.R., Petrishev S., Smirnov V., Ovodov Yu.S. // World J. Gastroenterol. 2006. Vol. 12. Pp. 6646-6651.

101. Gonda R., Tomoda M., Shimizu N., Kanari M. // Chem. Pharm. Bull. 1990. Vol. 38. Pp. 1966-1969.

102. Zhu H., Zhang Y., Zhang J., Chen D. // Int. Immunopharmacol. 2008. Vol. 8. Pp. 1222-1230.

103. Mestechkina N.M., Anulov O.V., Shcherbukhin V.D. // Appl. Biochem. Microbiol. 1998. Vol. 34. Pp. 497-500.

104. Muller B.M., Kraus J., Franz G. // Planta Med. 1989. Vol. 55. Pp. 536-539.

105. Alam N., Gupta P.C. // Planta Med. 1986. Vol. 52. Pp. 308-310.

106. Dzhumamuratova A., Seitmuratov E., Rakhimov D.A., Ismailov Z.F. // Chem. Nat. Comp. 1979. Vol. 14. Pp. 437.

107. Shimizu N., Tomoda M., Kanari M., Gonda R., Satoh A., Satoh H. // Chem. Pharm. Bull. 1990. Vol. 38. Pp. 3069-3071.

108. Shimizu N., Tomoda M., Takada K., Gonda R. // Chem. Pharm. Bull. 1992. Vol. 40. Pp. 2125-2128.

109. Tomoda M., Shimizu N., Kanari M., Gonda R., Arai S., Okuda Y. // Chem. Pharm. Bull. 1990. Vol. 38. Pp. 1667-1671.

110. Zhao J.-F., Kiyohara H., Yamada H., Takemoto N., Kawamura H. // Carbohydr. Res. 1991. Vol. 219. Pp. $149-172$.

111. Ghosh R., Sen P.C., Biswas S. // Mol. Cell. Biochem. 1998. Vol. 187. Pp. 47-55.

112. Patra P., Das D., Behera B., Maiti T.K., Islam S.S. // Carbohydr. Polym. 2012. Vol. 87. Pp. 2169-2175.

113. Smirnova N.I., Mestechkina N.M., Sherbukhin V.D. // Appl. Biochem. Microbiol. 2004. Vol. 40. Pp. 517-521.

114. Ramesh H.P., Yamaki K., Ono H., Tsushida T. // Carbohydr. Polym. 2001. Vol. 45. Pp. 69-77.

115. Hilz H., Bakx E.J., Schols H.A., Voragen A.G.J. // Carbohydr. Polym. 2005. Vol. 59. Pp. 477-488.

116. Kim Y.O., Park H.W., Kim J.H., Lee J.Y., Moon S.H., Shin C.S. // Life Sci. 2006. Vol. 79. Pp. 72-80.

117. Zhang L., Fan C., Liu S., Zang Z., Jiao L., Zhang L. // J. Med. Plant Res. 2011. Vol. 5. Pp. 1251-1260.

118. Olennikov D.N., Rokhin A.V., Agafonova S.V. // Chem. Nat. Comp. 2011. Vol. 47. Pp. 847-848.

119. Злобин А.А., Мартинсон Е.А., Овечкина И.А., Дурнев Е.А., Оводова Р.Г., Литвинец С.Г. // Химия растит. сырья. 2011. № 1. С. 33--38.

120. Sanavova M.Kh., Rakhimov D.A. // Chem. Nat. Comp. 2004. Vol. 40. Pp. 83-84.

121. Maruyama K., Goto C., Numata M., Suzuki T., Nakagawa Y., Hoshino T., Uchiyama T. // Phytochemistry. 1996. Vol. 41. Pp. 1309-1314.

122. Maruyama K., Yamamoto H., Uchiyama T. // Biosci. Biotech. Biochem. 1998. Vol. 62. Pp. 2223-2225.

123. Olennikov D.N., Tankhaeva L.M. // Chem. Nat. Comp. 2007. Vol. 43. Pp. 501-507.

124. Olennikov D.N., Tankhaeva L.M. // Chem. Nat. Comp. 2007. Vol. 43. Pp. 648-651.

125. Olennikov D.N., Tankhaeva L.M. // Chem. Nat. Comp. 2008. Vol. 44. Pp. 630-631.

126. Capek Pp. // Carbohydr. Polym. 2009. Vol. 75. Pp. 356-359.

127. Capek P., Hř́balová V. // Phytochemistry. 2004. Vol. 65. Pp. 1983-1992.

128. Capek P., Hř́balová V., Švandová E., Ebringerová A., Sasinková V., Masarová J. // Int. J. Biol. Macromol. 2003. Vol. 33. Pp. 113-119.

129. Olennikov D.N., Stolbikova A.V., Rokhin A.V., Khobrakova V.B. // Chem. Nat. Comp. 2011. Vol. 47. Pp. $190-193$.

130. Chun H., Jun W.J., Shin D.H., Hong B.S., Cho H.Y., Yang H.C. // Chem. Pharm. Bull. 2001. Vol. 49. Pp. $762-764$.

131. Chun H., Shin D.H., Hong B.S., Cho H.Y., Yang H.C. // Biol. Pharm. Bull. 2001. Vol. 24. Pp. 941-946.

132. Zvyagintseva T.N., Shevchenko N.M., Chizhov A.O., Krupnova T.N., Sundukova E.V., Isakov V.V. // J. Exp. Marine Biol. Ecol. 2003. Vol. 294. Pp. 1-13.

133. Naran R., Chen G., Carpita N.C. // Plant Physiol. 2008. Vol. 148. Pp. 132-141.

134. Warrand J., Michaud P., Picton L., Muller G., Courtois B., Ralainirina R., Courtois J. // J. Agric. Food Chem. 2005. Vol. 53. Pp. 1449-1459.

135. Warrand J., Michaud P., Picton L., Muller G., Courtois B., Ralainirina R., Courtois J. // Int. J. Biol. Macromol. 2005. Vol. 35. Pp. 121-125.

136. Andrews P., Hough L., Jones J.K.N. // J. Chem. Soc. 1954. Pp. 806-810.

137. Corsaro M.M., Giudicianni I., Lanzetta R., Marciano C.E., Monaco P., Parrilli M. // Phytochemistry. 1995. Vol. 39. Pp. 1377-1380. 
138. Capek P., Rosík J., Kardošova A., Toman R. // Carbohydr. Res. 1987. Vol. 164. Pp. 443-452.

139. Capek P., Toman R., Kardošová A., Rosík J. // Carbohydr. Res. 1983. Vol. 117. Pp. 133-140.

140. Tomoda M., Kaneko S., Ebashi M., Nagakura T. // Chem. Pharm. Bull. 1977. Vol. 25. Pp. 1357-1362.

141. Tomoda M., Satoh N., Shimada K. // Chem. Pharm. Bull. 1980. Vol. 28. Pp. 824-830.

142. Sagdullaev B.T., Shakhidoyatov R.Kh., Khodzhaeva M.A., Chernenko T.V., Turakhozhaev M.T., Abduazimova M.A. // Chem. Nat. Comp. 2001. Vol. 37. Pp. 208-212.

143. Kuduk-Jaworska J., Szpunar J., Gasiorowski K., Brokos B. // Z. Naturforsch. 2004. Vol. 59c. Pp. 485-493.

144. Buchala A.J., Franz G., Meier H. // Phytochemistry. 1974. Vol. 13. Pp. 163-166.

145. Song J.-Y., Yang H.-O., Pyo S.-N., Jung I.-S., Yi S.-Y., Yun Y.-S. // Arch. Pharm. Res. 2002. Vol. 25. Pp. $158-164$.

146. Wold J.K., Smestad B., Winsnes R., Resser D. // Acta Chem. Scand. 1970. Vol. 24. Pp. 1262-1270.

147. Rakhimov D.A., Igamberdieva M.I., Kondratenko E.S. // Chem. Nat. Comp. 1983. Vol. 19. Pp. $260-262$.

148. Samuelsen A.B., Paulsen B.S., Wold J.K., Otsuka H., Yamada H., Espevik T. // Phytoter. Res. 1995. Vol. 9. Pp. 211-218.

149. Samuelsen A.B., Paulsen B.S., Wold J.K., Otsuka H., Kiyohara H., Yamada H., Knutsen S.H. // Carbohydr. Polym. 1996. Vol. 30. Pp. 37-44.

150. Samuelsen A.B., Paulsen B.S., Wold J.K., Knutsen S.H., Yamada H. // Carbohydr. Polym. 1998. Vol. 35. Pp. $145-153$.

151. Edwards S., Chaplin M.F., Blackwood A.D., Dettmar P.W. // Proc. Nutr. Soc. 2003. Vol. 62. Pp. 217-222.

152. Guo Q., Cui S.W., Wang Q., Young J.C. // Carbohydr. Polym. 2008. Vol. 73. Pp. 35-43.

153. Yunuskhodzhaeva N.A., Abdullabekova V.N., Kurbanova A.D. // Chem. Nat. Comp. 2006. Vol. 42. Pp. $600-601$.

154. Martynov E.G., Makarov D.Yu., Panov V.L., Martynov A.E. // Chem. Nat. Comp. 1986. Vol. 22. Pp. $473-474$.

155. Чушенко В.Н., Яцюк В.Я., Комисаренко Н.Ф., Карамова О.Б. // Растит. ресурсы. 1995. Т. 31. С. 97-99.

156. Yakovlev A.I., Martynov E.G. // Chem. Nat. Comp. 1979. Vol. 15. Pp. 69.

157. Kuliev V.B., Poletaeva L.V. // Chem. Nat. Comp. 1985. Vol. 18. Pp. 612-613.

158. Pawlaczyk I., Czerchawski L., Pilecki W., Lamer-Zarawska E., Gancarz R. // Carbohydr. Polym. 2009. Vol. 77. Pp. 568-575.

159. Khodzhaeva M.A., Sagdullaev B.T., Turakhozhaev M.T., Aripov Kh.N. // Chem. Nat. Comp. 1998. Vol. 34. Pp. $736-737$.

160. Kim Y.S., Roh J.E., Ann H.S. // Korean J. Pharmacogn. 1993. Vol. 24. Pp. 124--130.

161.Злобин А.А., Мартинсон Е.А., Литвинец С.Г., Овечкина И.А., Дурнев Е.А., Оводова Р.Г. // Химия раститительного сырья. 2011. №1. С. 39-44.

162. Fujiwara T., Arai K. // Carbohydr. Res. 1982. Vol. 101. Pp. 305-313.

163. Rakhimov D.A., Zakirova R.P. // Chem. Nat. Comp. 2002. Vol. 38. Pp. 350-351.

164. Golovchenko V.V., Bushneva O.A., Ovodova R.G., Shashkov A.S., Chizhov A.O., Ovodov Yu.S. // Russ. J. Bioorg. Chem. 2007. Vol. 33. Pp. 47-56.

165. Popov S.V., Ovodova R.G., Golovchenko V.V., Popova G.Y., Viatyasev F.V., Shashkov A.S., Ovodov Y.S. // Food Chem. 2011. Vol. 124. Pp. 309-315.

166. Yakovlev A.I. // Chem. Nat. Comp. 1985. Vol. 21. Pp. 114.

167. Wagner H., Willer F., Kreher B. // Planta Med. 1989. Vol. 55. Pp. 452-454.

168. Ebringerová A., Kardošová A., Hromádková Z., Hř́́balová V. // Fitoterapia. 2003. Vol. 74. Pp. 52-61.

169. Оводова Р.Г., Головченко В.В., Попов С.В. // Химия растительного сырья. 1999. №1. С. 53-57.

170. Zabaznaya E.I. // Chem. Nat. Comp. 1985. Vol. 21. Pp. 113.

171. Jordan E., Wagner H. // Oncology. 1988. Vol. 43 (Suppl. 1). Pp. 8-15.

172. Huang X.L, Zhang Y.S., Liang Z.Y. // Acta Pharm. Sin. 1991. Vol. 26. Pp. 578-583.

173. Chen H.S., Leung W.N., Xu Y.X. // Chin. Chem. Lett. 2002. Vol. 13. Pp. 625-628.

174. Olennikov D.N., Tankhaeva L.M., Samuelsen A.B. // Chem. Nat. Comp. 2006. Vol. 42. Pp. 265-268.

175. Olennikov D.N., Tankhaeva L.M. // Russ. J. Bioorg. Chem. 2011. Vol. 37. Pp. 819-827.

176. Olennikov D.N., Agafonova S.V., Borovskii G.B., Penzina T.A., Rokhin A.V. // Appl. Biochem. Microbiol. 2009. Vol. 45. Pp. 536-543.

177. Olennikov D.N., Rokhin A.V., Tankhaeva L.M. // Chem. Nat. Comp. 2009. Vol. 45. Pp. 300-303.

178. Olennikov D.N., Stolbikova A.V., Tankhaeva L.M., Petrov E.V. // Chem. Nat. Comp. 2011. Vol. 47. Pp. $165-169$.

179. Olennikov D.N., Agafonova S.V., Rokhin A.V., Borovskii G.B., Penzina T.A. // Appl. Biochem. Microbiol. 2012. Vol. 48. Pp. 65-70.

180. Olennikov D.N., Stolbikova A.V., Rokhin A.V., Khobrakova V.B., Tankhaeva L.M. // Chem. Nat. Comp. 2011. Vol. 47. Pp. 1-6.

181. Olennikov D.N., Rokhin A.V. // Chem. Nat. Comp. 2011. Vol. 47. Pp. 343-346.

182. Olennikov D.N., Tankhaeva L.M., Rokhin A.V. // Chem. Nat. Comp. 2011. Vol. 47. Pp. 349-342.

183. Olennikov D.N., Nazarova A.V., Rokhin A.V., Tankhaeva L.M., Kornopol'tseva T.V. // Chem. Nat. Comp. 2009. Vol. 45. Pp. 811-814.

184. Togola A., Inngjerdingen M., Diallo D., Barsett H., Rolstad B., Michaelsen T.E., Paulsen B.S. // J. Ethnopharmacol. 2007. Vol. 115. Pp. 423-431. 
Olennikov D.N. , Kashchenko N.I. POLYSACCHARIDES. CURRENT STATE OF KNOWLEDGE: AN EXPERIMENTAL AND SCIENTOMETRIC INVESTIGATION

Institute of General and Experimental Biology SD RAS, Sakh'yanovoy str., 6, Ulan-Ude, 670047 (Russian Federation), e-mail: oldaniil@rambler.ru

In review the results of scientometric study of information from scientific literature about the state of knowledge of one of the most widespread groups of natural polymers - polysaccharides, are presented. To perform the study used the resources of the scientific database Scopus. The data generalization about polysaccharide components of plant species permitted for use in medical practice in Russia (112 species) were performed; the information on the distribution of polysaccharide classes in plants morphological groups was provides. The experimental part of the work included the determination of the content and group membership for water-soluble polysaccharides from 84 officinal plant species, for 56 of which such study was carried out for the first time.

Keywords: polysaccharides, scientometric analysis, keyword, citing, officinal plant species, morphological groups

\section{References}

1. Baker J.L., Pope T.H. J. Chem. Soc. Trans., 1990, vol. 77, pp. 696-705.

2. Dubois M., Gilles K.A., Hamilton J.K., Rebers P.A., Smith F. Anal. Chem., 1956, vol. 28, pp. 350-356.

3. Van Soest P.J., Robertson J.B., Lewis B.A. J. Dairy Sci., 1991, vol. 74, pp. 3583-3597.

4. Carpita N.C., Gibeaut D.M. Plant J., 1993, vol. 3, pp. 1-30.

5. Schleifer K.H., Kandler O. Bacteriol. Rev., 1972, vol. 36, pp. 407-477.

6. Raetz C.R.H., Whitfield C. Ann. Rev. Biochem., 1992, vol. 71, pp. 635-700.

7. Laurent T.C., Fraser J.R.E. FASEB J., 1992, vol. 6. Pp. 2397-2404.

8. Ravi Kumar M.N.V. React. Funct. Polym., 2000, vol. 46, pp. 1-27.

9. Helenius A., Aebi M. Science., 2001, vol. 291, pp. 2364-2369.

10. Hakomori S.-I. J. Biochem., 1964, vol. 55, pp. 205-208.

11. Englyst H.N., Kingman S.M., Cummings J.H. Eur. J. Clin. Nutr., 1992, vol. 46 (Suppl. 2), pp. S33-S50.

12. Gibson G.R., Beatty E.R., Wang X., Cummings J.H. Gastroenterology. 1995, vol. 108, pp. 975-982.

13. Stevenson T.T., Furneaux R.H. Carbohydr. Res., 1991, vol. 210, pp. 277-298.

14. Ridley B.L., O'Neill M.A., Mohnen D. Phytochemistry. 2001, vol. 57, pp. 929-967.

15. Rowley J.A., Madlambayan G., Mooney D.J. Biomaterials. 1999, vol. 20, pp. 45-53.

16. Patankar M.S., Oehninger S., Barnett T., Williams R.L., Clark G.F. J. Biol. Chem. 1993, vol. 268, pp. 21770-21776.

17. Wang Y.P. Chin. J. Modern Develop. Trad. Med., 1991, vol. 11, pp. 61-63.

18. He L., Guo-Ying Z., Jian-Ping X., Jun-Ang L., Huai-Yun Z., Yimin T. J. Med. Plant Res., 2012, vol. 6, pp. 171-176.

19. Sun Y. Carbohydr. Polym., 2011, vol. 85, pp. 490-499.

20. Gupta V., Puri R., Gupta S., Jain S., Rao G.K. Syst. Rev. Pharm., 2010, vol. 1, pp. 50-54.

21. Mathur V., Mathur N.K. J. Sci. Ind. Res., 2005, vol. 64, pp. 475-481.

22. Zhong S., Pan H., Fan L., Lv G., Wu Y., Parmeswaran B., Pandey A., Soccol C.R. Food Technol. Biotechnol., 2009, vol. 47, pp. 304-312.

23. Houseknecht J.B., Lowary T.L. Curr. Opin. Chem. Biol., 2001, vol. 5, pp. 677-682.

24. Shcherbukhin V.D. Prikl. biokhim. mikrobiol., 1993, vol. 29, pp. 803-813. (in Russ.).

25. Shcherbukhin V.D., Anulov O.V. Prikl. biokhim. mikrobiol., 1999, vol. 35, pp. 257-274. (in Russ.).

26. Srivastava M., Kapoor V.P. Chem. Biodiv., 2005, vol. 2, pp. 295-317.

27. Arifkhodzhaev A.O. Chem. Nat. Comp., 1997, vol. 33, pp. 1-10.

28. Paulsen B.S., Barsett H. Adv. Polym. Sci., 2005, vol. 186, pp. 69-101.

29. Yapo B.M. Carbohydr. Polym., 2011, vol. 86, pp. 373-385.

30. Berteau O., Mulloy B. Glycobiology, 2003, vol. 13, pp. 29R-40R.

31. Shibata N., Okawa Y. Jap. J. Med. Mycol., 2006, vol. 47, pp. 179-184.

32. Willför S., Sundberg A., Pranovich A., Holmbom B. Wood Sci. Technol., 2005, vol. 39, pp. 601-617.

33. Olafsdottir E.S., Ingólfsdottir K. Planta Med., 2001, vol. 67, pp. 199-208.

34. Senni K., Pereira J., Gueniche F., Delbarre-Ladrat C., Sinquin C., Ratiskol J., Godeau G. Marine Drugs, 2011, vol. 9 , p. 1664-1681.

35. Kelly G.S. Altern. Med. Rev., 1999, vol. 4, pp. 96-103.

36. Barclay T., Ginic-Markovic M., Cooper P., Petrovsky N. J. Excip. Food Chem., 2010, vol. 1, pp. $27-50$.

37. Jezequel V. Cer. Foods World., 1998, vol. 43, pp. 361-364.

38. Nio Y., Itakura M., Yano S., Sumi S.-I., Tamura K. Biotherapy, 2000, vol. 14, pp. 849-858.

39. O'Neill M.A., Ishii T., Albersheim P., Darvill A.G. Ann. Rev. Plant Biol., 2004, vol. 55, pp. 109-139.

40. Pérez S., Rodríguez-Carvajal M.A., Doco T. Biochimie, 2004, vol. 85, pp. 109-121.

41. Coviello T., Palleschi A., Grassi M., Matricardi P., Bocchinfuso G., Alhaique F. Molecules, 2005, vol. 10, pp. 6-33.

42. Leung M.Y.K., Liu C., Koon J.C.M., Fung K.P. Immunol. Lett., 2006, vol. 105, pp. 101-114.

43. Paulsen B.S. Curr. Org. Chem., 2001, vol. 5, pp. 939-950.

44. Ramberg J.E., Nelson E.D., Sinnott R.A. Nutrit. J., 2010, vol. 9. Art. no. 54.

45. Schepetkin I.A., Quinn M.T. Int. Immunopharmacol., 2006, vol. 6, pp. 317-333.

\footnotetext{
* Corresponding author.
} 
46. Lin M.-G., Yang Y.-F., Li Y.-H. Chin. Trad. Herb. Drugs, 2007, vol. 38, pp. 949-953.

47. Ma M.-H., Yi Y.-H., Tang H.-F. Pharm. Care Res., 2004, vol. 4, pp. 305-308.

48. Rakhimov D.A., Kondratenko E.S., Khamidkhodzhaev S.A. Chem. Nat. Comp., 1983, vol. 19, pp. 601-602.

49. Ishii S. Phytochemistry, 1982, vol. 21, pp. 778-780.

50. Khodzhaeva M.A., Kondratenko E.S. Chem. Nat. Comp., 1984, vol. 20, pp. 358-359.

51. Redgwell R.J., Selvendran R.R. Carbohydr. Res., 1986, vol. 157, pp. 183-199.

52. Das N.N., Das A. Carbohydr. Res., 1978, vol. 64, pp. 155-167.

53. Das N.N., Das A., Kumar Mukherjee A. Carbohydr. Res., 1977, vol. 56, pp. 337-349.

54. Khodzhaeva M.A., Ismailov Z.F. Chem. Nat. Comp., 1979, vol. 15, pp. 114-118.

55. Mallabaev A., Rakhimov D.A., Murdakhaev Yu.M. Chem. Nat. Comp., 1989, vol. 25, pp. 369-370.

56. Polyakova N.S., Rakhimov D.A., Kondratenko E.S. Chem. Nat. Comp., 1984, vol. 20, pp. 612-614.

57. Patra S., Maity K.K., Bhunia S.K., Dey B., Das D., Mondal S., Bhunia B. Carbohydr. Polym., 2010, vol. 81, pp. 584-591.

58. Carbik I., Baser K.H.C., Ozel H.Z., Ergun B., Wagner H. Planta Med., 1990, vol. 56, pp. 668.

59. Muller B.M., Rosskopf F., Paper D.H., Kraus J., Franz G. Pharmazie, 1991, vol. 46, pp. 657-663.

60. Kozlova R.Iu., Klochkov V.V., Vinter V.G. Uchenye zapiski Kazanskogo gosudarstvennogo universiteta, 2007, vol. 149, pp. 125-137. (in Russ.).

61. Popov S.V., Vinter V.G., Patova O.A., Markov P.A., Nikitina I.R., Ovodova R.G., Popova G.Yu., Ovodov Yu.S. Biochemistry (Moscow), 2007, vol. 72, pp. 778-784.

62. Belska N.V., Guriev A.M., Danilets M.G., Trophimova E.S., Uchasova E.G., Ligatcheva A.A., Belousov M.V., Belsky Y.P. Int. Immunopharmacol., 2010, vol. 10, pp. 933-942.

63. Solov'eva T.F., Prudnikova T.I., Ovodov Iu.S. Rastititel'nye resursy, 1968, vol. 4, pp. 497-501.

64. Chen R., Liu Z., Zhao J., Chen R., Meng F., Zhang M., Ge W. Food Chem., 2011, vol. 127, pp. 434-440.

65. Fang J.-N., Proksch A., Wagner H. Phytochemistry, 1985, vol. 24, pp. 2619-2622.

66. Hikino H., Takahashi M., Otake K., Konno C. J. Nat. Prod., 1986, vol. 49, pp. 293-297.

67. Ovodov Yu.S., Shibaeva V.I. Chem. Nat. Comp., 1969, vol. 5, pp. 501.

68. Ovodova R.G., Lapchik V.F., Ovodov Yu.S. Chem. Nat. Comp., 1975, vol. 11, pp. 1-2.

69. Yagi A., Makino K., Nishioka I., Kuchino Y. Planta Med., 1977, vol. 31, pp. 17-20.

70. Olennikov D.N., Nazarova A.V., Rokhin A.V. Chem. Nat. Comp., 2009, vol. 45, pp. 611-614.

71. Zhauynbaeva K.S., Rakhimov D.A., Nigmatullaev A.A. Chem. Nat. Comp., 2010, vol. 46, pp. 783-784.

72. Hopf H., Kandler O. Phytochemistry, 1977, vol. 16, pp. 1715-1717.

73. Saluk-Juszczak J., Pawlaczyk I., Olas B., Kołodziejczyk J., Ponczek M., Nowak P., Tsirigotis-Wołoszczak M. Int. J. Biol. Macromol., 2010, vol. 47, pp. 700-705.

74. Kardošová A., Ebringerová A., Alföldi J., Nosál'ová G., Fraňová S., Hříbalová V. Int. J. Biol. Macromol., 2003 , vol. 33, pp. 135-140.

75. Kato Y., Watanabe T. Biosci. Biotech. Biochem., 1993, vol. 57, pp. 1591-1592.

76. Turdumambetov K., Bakirov G.A., Rakhimov D.A. Chem. Nat. Comp., 2004, vol. 40, pp. 211-214.

77. Puhlmann J., Wagner H. Planta Med., 1989, vol. 55, pp. 99.

78. Varljen J., Lipták A., Wagner H. Phytochemistry., 1989, vol. 28, pp. 2379-2383.

79. Garbacki N., Gloaguen V., Damas J., Bodart P., Tits M., Angenot L. J. Ethnopharmacol., 1999, vol. 68, pp. $235-241$.

80. Chamomile: industrial profiles. Eds. R. Franke, H. Schilcher. Medicinal and Aromatic Plants - industrial profiles, vol. 42. Boca Raton, London, New York, Singapore: Taylor \& Francis, 2005. 280 p.

81. Bacon J.S.D., Edelman J. Biochem. J., 1951, vol. 48, pp. 114-126.

82. Proksch A., Wagner H. Phytochemistry, 1987, vol. 26, pp. 1989-1993.

83. Wagner H., Stuppner H., Schäfer W., Zenk M. Phytochemistry, 1988, vol. 27, pp. 119-126.

84. Luettig B., Steinmuller C., Gifford G.E., Wagner H., Lohmann-Matthes M.-L. J. Nat. Cancer Inst., 1989, vol. 81, pp. 669-675.

85. Bell D.J., Palmer A. J. Chem. Soc., 1952, pp. 3741-3744.

86. Polle A.Ya., Ovodova R.G., Chizhov A.O., Shashkov A.S., Ovodov Yu.S. Biochemistry (Moscow), 2002, vol. 67, pp. 1371-1376.

87. Xie G., Schepetkin I.A., Quinn M.T. Int. Immunopharmacol., 2007, vol. 7, pp. 1639-1650.

88. Ernst M., Chatterton N.J., Harrison P.A. New Phytol., 1996, vol. 132, pp. 63-66.

89. Olennikov D.N., Tankhaeva L.M., Rokhin A.V. Chem. Nat. Comp., 2009, vol. 45, pp. 141-144.

90. Haaland E. Acta Chem. Scand., 1969, vol. 23, pp. 2546-2548.

91. Henderson G.A., Hay G.W. Carbohydr. Res., 1972, vol. 23, pp. 379-398.

92. Martynov E.G., Stroev E.A., Peskov D.D. Chem. Nat. Comp., 1984, vol. 20, pp. 99-100.

93. Makhatadze M., Bostoganashvili A.M., Barbakadze V., Kemertelidze E., Dekanosidze H. Ann. New York Acad. Sci. 1993, vol. 685, pp. 383-385.

94. Tharanathan R.N., Ramadas Bhat U., Murali Krishna G., Paramahans S.V. Phytochemistry, 1985, vol. 24, pp. $2722-2723$.

95. Oosterveld A., Voragen A.G.J., Schols H.A. Carbohydr. Polym., 2002, vol. 49, pp. 407-413.

96. Chushenko V.N., Vinnik E.V., Komissarenko N.F., Stupakova E.P., Petukhova T.V., Zinchenko V.V. Chem. Nat. Comp., 1992, vol. 28, pp. 242-243.

97. Wang G., Liang Z., Zhang L. Chin. Pharm. J., 1999, vol. 34, pp. 229-231.

98. Olennikov D.N., Nazarova A.V. Chem. Nat. Comp., 2009, vol. 45, pp. 702-703. 
99. Ovodov Iu.S., Golovchenko V.V., Giunter E.A., Popov S.V. Pektinovye veshchestva rastenii evropeiskogo severa Rossii. [Pectin plants of European North of Russia.]. Yekaterinburg,2009, 112 p. (in Russ.).

100. Popov S.V., Markov P.A., Nikitina I.R., Petrishev S., Smirnov V., Ovodov Yu.S. World J. Gastroenterol., 2006, vol. 12, pp. 6646-6651.

101. Gonda R., Tomoda M., Shimizu N., Kanari M. Chem. Pharm. Bull., 1990, vol. 38, pp. 1966-1969.

102. Zhu H., Zhang Y., Zhang J., Chen D. Int. Immunopharmacol., 2008, vol. 8, pp. 1222-1230.

103. Mestechkina N.M., Anulov O.V., Shcherbukhin V.D. Appl. Biochem. Microbiol., 1998, vol. 34, pp. 497-500.

104. Muller B.M., Kraus J., Franz G. Planta Med., 1989, vol. 55, pp. 536-539.

105. Alam N., Gupta P.C. Planta Med., 1986, vol. 52, pp. 308-310.

106. Dzhumamuratova A., Seitmuratov E., Rakhimov D.A., Ismailov Z.F. Chem. Nat. Comp., 1979, vol. 14, pp. 437.

107. Shimizu N., Tomoda M., Kanari M., Gonda R., Satoh A., Satoh H. Chem. Pharm. Bull., 1990, vol. 38, pp. 3069-3071.

108. Shimizu N., Tomoda M., Takada K., Gonda R. Chem. Pharm. Bull., 1992, vol. 40, pp. 2125-2128.

109. Tomoda M., Shimizu N., Kanari M., Gonda R., Arai S., Okuda Y. Chem. Pharm. Bull., 1990, vol. 38, pp. 1667-1671.

110. Zhao J.-F., Kiyohara H., Yamada H., Takemoto N., Kawamura H. Carbohydr. Res., 1991, vol. 219, pp. $149-172$.

111. Ghosh R., Sen P.C., Biswas S. Mol. Cell. Biochem., 1998, vol. 187, pp. 47-55.

112. Patra P., Das D., Behera B., Maiti T.K., Islam S.S. Carbohydr. Polym., 2012, vol. 87, pp. 2169-2175.

113. Smirnova N.I., Mestechkina N.M., Sherbukhin V.D. Appl. Biochem. Microbiol., 2004, vol. 40, pp. 517-521.

114. Ramesh H.P., Yamaki K., Ono H., Tsushida T. Carbohydr. Polym., 2001, vol. 45, pp. 69-77.

115. Hilz H., Bakx E.J., Schols H.A., Voragen A.G. J. Carbohydr. Polym., 2005, vol. 59, pp. 477-488.

116. Kim Y.O., Park H.W., Kim J.H., Lee J.Y., Moon S.H., Shin C.S. Life Sci., 2006, vol. 79, pp. 72-80.

117. Zhang L., Fan C., Liu S., Zang Z., Jiao L., Zhang L. J. Med. Plant Res., 2011, vol. 5, pp. 1251-1260.

118. Olennikov D.N., Rokhin A.V., Agafonova S.V. Chem. Nat. Comp,. 2011, vol. 47, pp. 847-848.

119.Zlobin A.A., Martinson E.A., Ovechkina I.A., Durnev E.A., Ovodova R.G., Litvinets S.G. Khimiia rastitel'nogo syr'ia, 2011, no. 1, pp. 33--38.

120. Sanavova M.Kh., Rakhimov D.A. Chem. Nat. Comp., 2004, vol. 40, pp. 83-84.

121. Maruyama K., Goto C., Numata M., Suzuki T., Nakagawa Y., Hoshino T., Uchiyama T. Phytochemistry, 1996 , vol. 41, pp. 1309-1314.

122. Maruyama K., Yamamoto H., Uchiyama T. Biosci. Biotech. Biochem., 1998, vol. 62, pp. 2223-2225.

123. Olennikov D.N., Tankhaeva L.M. Chem. Nat. Comp., 2007, vol. 43, pp. 501-507.

124. Olennikov D.N., Tankhaeva L.M. Chem. Nat. Comp., 2007, vol. 43, pp. 648-651.

125. Olennikov D.N., Tankhaeva L.M. Chem. Nat. Comp., 2008, vol. 44, pp. 630-631.

126. Capek P. Carbohydr. Polym., 2009, vol. 75, pp. 356-359.

127. Capek P., Hř́balová V. Phytochemistry, 2004, vol. 65, pp. 1983-1992.

128. Capek P., Hř́ibalová V., Švandová E., Ebringerová A., Sasinková V., Masarová J. Int. J. Biol. Macromol., 2003, vol. 33, pp. 113-119.

129. Olennikov D.N., Stolbikova A.V., Rokhin A.V., Khobrakova V.B. Chem. Nat. Comp., 2011, vol. 47, pp. $190-193$.

130. Chun H., Jun W.J., Shin D.H., Hong B.S., Cho H.Y., Yang H.C. Chem. Pharm. Bull., 2001, vol. 49, pp. $762-764$.

131. Chun H., Shin D.H., Hong B.S., Cho H.Y., Yang H.C. Biol. Pharm. Bull., 2001, vol. 24, pp. 941-946.

132. Zvyagintseva T.N., Shevchenko N.M., Chizhov A.O., Krupnova T.N., Sundukova E.V., Isakov V.V. J. Exp. Marine Biol. Ecol., 2003, vol. 294, pp. 1-13.

133. Naran R., Chen G., Carpita N.C. Plant Physiol., 2008, vol. 148, pp. 132-141.

134. Warrand J., Michaud P., Picton L., Muller G., Courtois B., Ralainirina R., Courtois J. J. Agric. Food Chem., 2005, vol. 53, pp. 1449-1459.

135. Warrand J., Michaud P., Picton L., Muller G., Courtois B., Ralainirina R., Courtois J. Int. J. Biol. Macromol., 2005, vol. 35, pp. 121-125.

136. Andrews P., Hough L., Jones J.K.N. J. Chem. Soc., 1954, pp. 806-810.

137. Corsaro M.M., Giudicianni I., Lanzetta R., Marciano C.E., Monaco P., Parrilli M. Phytochemistry, 1995, vol. 39, pp. $1377-1380$.

138. Capek P., Rosík J., Kardošova A., Toman R. Carbohydr. Res., 1987, vol. 164, pp. 443-452.

139. Capek P., Toman R., Kardošová A., Rosík J. Carbohydr. Res., 1983, vol. 117, pp. 133-140.

140. Tomoda M., Kaneko S., Ebashi M., Nagakura T. Chem. Pharm. Bull., 1977, vol. 25, pp. 1357-1362.

141. Tomoda M., Satoh N., Shimada K. Chem. Pharm. Bull., 1980, vol. 28, pp. 824-830.

142. Sagdullaev B.T., Shakhidoyatov R.Kh., Khodzhaeva M.A., Chernenko T.V., Turakhozhaev M.T., Abduazimova M.A. Chem. Nat. Comp., 2001, vol. 37, pp. 208-212.

143. Kuduk-Jaworska J., Szpunar J., Gasiorowski K., Brokos B. Z. Naturforsch., 2004, vol. 59c, pp. 485-493.

144. Buchala A.J., Franz G., Meier H. Phytochemistry, 1974, vol. 13, pp. 163-166.

145. Song J.-Y., Yang H.-O., Pyo S.-N., Jung I.-S., Yi S.-Y., Yun Y.-S. Arch. Pharm. Res., 2002, vol. 25, pp. $158-164$.

146. Wold J.K., Smestad B., Winsnes R., Resser D. Acta Chem. Scand., 1970, vol. 24, pp. 1262-1270.

147. Rakhimov D.A., Igamberdieva M.I., Kondratenko E.S. Chem. Nat. Comp., 1983, vol. 19, pp. 260-262.

148. Samuelsen A.B., Paulsen B.S., Wold J.K., Otsuka H., Yamada H., Espevik T. Phytoter. Res., 1995, vol. 9, pp. $211-218$.

149. Samuelsen A.B., Paulsen B.S., Wold J.K., Otsuka H., Kiyohara H., Yamada H., Knutsen S.H. Carbohydr. Polym., 1996, vol. 30, pp. 37-44.

150. Samuelsen A.B., Paulsen B.S., Wold J.K., Knutsen S.H., Yamada H. Carbohydr. Polym., 1998, vol. 35, pp. 145-153. 
151. Edwards S., Chaplin M.F., Blackwood A.D., Dettmar P.W. Proc. Nutr. Soc., 2003, vol. 62, pp. 217-222.

152. Guo Q., Cui S.W., Wang Q., Young J.C. Carbohydr. Polym., 2008, vol. 73, pp. 35-43.

153. Yunuskhodzhaeva N.A., Abdullabekova V.N., Kurbanova A.D. Chem. Nat. Comp., 2006, vol. 42, pp. 600-601.

154. Martynov E.G., Makarov D.Yu., Panov V.L., Martynov A.E. Chem. Nat. Comp., 1986, vol. 22, pp. $473-474$.

155. Chushenko V.N., Iatsiuk V.Ia., Komisarenko N.F., Karamova O.B. Rastitel'nye resursy, 1995, vol. 31, pp. 97-99. (in Russ.).

156. Yakovlev A.I., Martynov E.G. Chem. Nat. Comp., 1979, vol. 15, pp. 69.

157. Kuliev V.B., Poletaeva L.V. Chem. Nat. Comp., 1985, vol. 18, pp. 612-613.

158. Pawlaczyk I., Czerchawski L., Pilecki W., Lamer-Zarawska E., Gancarz R. Carbohydr. Polym., 2009, vol. 77, pp. 568-575.

159. Khodzhaeva M.A., Sagdullaev B.T., Turakhozhaev M.T., Aripov Kh.N. Chem. Nat. Comp., 1998, vol. 34, pp. $736-737$.

160. Kim Y.S., Roh J.E., Ann H.S. Korean J. Pharmacogn, 1993, vol. 24, pp. 124-130.

161.Zlobin A.A., Martinson E.A., Litvinets S.G., Ovechkina I.A., Durnev E.A., Ovodova R.G. Khimiia rastititel'nogo syr'ia, 2011, no. 1, pp. 39-44. (in Russ.).

162. Fujiwara T., Arai K. Carbohydr. Res., 1982, vol. 101, pp. 305-313.

163. Rakhimov D.A., Zakirova R.P. Chem. Nat. Comp., 2002, vol. 38, pp. 350-351.

164. Golovchenko V.V., Bushneva O.A., Ovodova R.G., Shashkov A.S., Chizhov A.O., Ovodov Yu.S. Russ. J. Bioorg. Chem., 2007, vol. 33, pp. 47-56.

165. Popov S.V., Ovodova R.G., Golovchenko V.V., Popova G.Y., Viatyasev F.V., Shashkov A.S., Ovodov Y.S. Food Chem., 2011, vol. 124, pp. 309-315.

166. Yakovlev A.I. Chem. Nat. Comp., 1985, vol. 21, pp. 114.

167. Wagner H., Willer F., Kreher B. Planta Med., 1989, vol. 55, pp. 452-454.

168. Ebringerová A., Kardošová A., Hromádková Z., Hříbalová V. Fitoterapia, 2003, vol. 74, pp. 52-61.

169. Ovodova R.G., Golovchenko V.V., Popov S.V. Khimiia rastitel'nogo syr'ia, 1999, no. 1, pp. 53-57.

170.Zabaznaya E.I. Chem. Nat. Comp., 1985, vol. 21, pp. 113.

171. Jordan E., Wagner H. Oncology, 1988, vol. 43 (Suppl. 1), pp. 8-15.

172. Huang X.L, Zhang Y.S., Liang Z.Y. Acta Pharm. Sin., 1991, vol. 26, pp. 578-583.

173. Chen H.S., Leung W.N., Xu Y.X. Chin. Chem. Lett., 2002, vol. 13, pp. 625-628.

174. Olennikov D.N., Tankhaeva L.M., Samuelsen A.B. Chem. Nat. Comp., 2006, vol. 42, pp. 265-268.

175. Olennikov D.N., Tankhaeva L.M. Russ. J. Bioorg. Chem., 2011, vol. 37, pp. 819-827.

176. Olennikov D.N., Agafonova S.V., Borovskii G.B., Penzina T.A., Rokhin A.V. Appl. Biochem. Microbiol., 2009, vol. 45, pp. 536-543.

177. Olennikov D.N., Rokhin A.V., Tankhaeva L.M. Chem. Nat. Comp., 2009, vol. 45, pp. 300-303.

178. Olennikov D.N., Stolbikova A.V., Tankhaeva L.M., Petrov E.V. Chem. Nat. Comp., 2011, vol. 47, pp. $165-169$.

179. Olennikov D.N., Agafonova S.V., Rokhin A.V., Borovskii G.B., Penzina T.A. Appl. Biochem. Microbiol., 2012, vol. 48 , pp. $65-70$.

180. Olennikov D.N., Stolbikova A.V., Rokhin A.V., Khobrakova V.B., Tankhaeva L.M. Chem. Nat. Comp., 2011, vol. 47, pp. 1-6.

181. Olennikov D.N., Rokhin A.V. Chem. Nat. Comp., 2011, vol. 47, pp. 343-346.

182. Olennikov D.N., Tankhaeva L.M., Rokhin A.V. Chem. Nat. Comp., 2011, vol. 47, pp. 349-342.

183. Olennikov D.N., Nazarova A.V., Rokhin A.V., Tankhaeva L.M., Kornopol'tseva T.V. Chem. Nat. Comp., 2009, vol. 45, pp. 811-814.

184. Togola A., Inngjerdingen M., Diallo D., Barsett H., Rolstad B., Michaelsen T.E., Paulsen B.S. J. Ethnopharmacol, 2007, vol. 115, pp. 423-431. 